\title{
Evolutionary history and stress regulation of the lectin superfamily in higher plants
}

Shu-Ye Jiang, Zhigang Ma, Srinivasan Ramachandran*

\begin{abstract}
Background: Lectins are a class of carbohydrate-binding proteins. They play roles in various biological processes. However, little is known about their evolutionary history and their functions in plant stress regulation. The availability of full genome sequences from various plant species makes it possible to perform a whole-genome exploration for further understanding their biological functions.

Results: Higher plant genomes encode large numbers of lectin proteins. Based on their domain structures and phylogenetic analyses, a new classification system has been proposed. In this system, 12 different families have been classified and four of them consist of recently identified plant lectin members. Further analyses show that some of lectin families exhibit species-specific expansion and rapid birth-and-death evolution. Tandem and segmental duplications have been regarded as the major mechanisms to drive lectin expansion although retrogenes also significantly contributed to the birth of new lectin genes in soybean and rice. Evidence shows that lectin genes have been involved in biotic/abiotic stress regulations and tandem/segmental duplications may be regarded as drivers for plants to adapt various environmental stresses through duplication followed by expression divergence. Each member of this gene superfamily may play specialized roles in a specific stress condition and function as a regulator of various environmental factors such as cold, drought and high salinity as well as biotic stresses.

Conclusions: Our studies provide a new outline of the plant lectin gene superfamily and advance the understanding of plant lectin genes in lineage-specific expansion and their functions in biotic/abiotic stress-related developmental processes.
\end{abstract}

\section{Background}

Lectins are carbohydrate-binding proteins that specifically recognize diverse sugar structures and mediate a variety of biological processes [1,2]. Lectin proteins contain at least one carbohydrate-binding domain. Based on this, three major types of lectins are distinguished, namely merolectins, hololectins and chimerolectins [3]. The merolectins have only single carbohydrate-binding domain and the hololectins contain two or more domains which are either identical or very homologous. The chimerolectins are fusion proteins consisting of one or more carbohydrate-binding domains and unrelated domains. Lectins are ubiquitous in nature, found in all kinds of organisms, from virus to humans [4]. Plant lectins are usually considered as a very heterogeneous

\footnotetext{
* Correspondence: sri@tll.org.sg

Temasek Life Sciences Laboratory, 1 Research Link, the National University of Singapore, Singapore 117604
}

group of proteins because comparative biochemical studies clearly indicate that they differ from each other with respect to their biochemical/physicochemical properties, molecular structure, carbohydrate-binding specificity and biological activities [5]. Therefore, it is difficult to find a widely acceptable way to classify plant lectins. Currently, several attempts have been made to group plant lectins. One of them was based on the carbohydrate-binding specificity. As a result, mannose- mannose/glucose-, mannose/maltose-, Gal/GalNAc, GlcNAc/(GlcNAc) $)^{-}$, fucose- and salic acid-binding lectins have been distinguished $([5,6]$. This classification emphasizes the use of lectins as tools with different carbohydrate-binding specificity. However, evolutionarily unrelated lectins may also be classified together. Besides this, another classification has been suggested, which is based on 3D structures of lectins. They classified lectins as 6 major groups including $\alpha$-D-mannose-specific plant 
lectin (monocot lectin), agglutinin with hevein domain, $\beta$-prism plant lectin, $\beta$-trefoil lectin, cyanovirin- $\mathrm{N}$ homolog and legume lectin http://www.cermav.cnrs.fr/ lectines/. Besides these, a more complicated classification system has been proposed which is based on either serological relationships or sequence similarities or both as well as their evolutionary relationships. Based on such criterion, 7 lectin families have been classified including the legume lectins, the monocot mannosebinding lectins, the chitin-binding lectins, the type 2 RIP and related lectins, jacalin-related lectins, Amaranthin lectins and Cucurbitaceae phloem lectins [6]. Recently, these authors made an update of the system since many new plant lectins have been isolated and characterized [7]. They have classified plant lectins into 12 families and at least one member in each family has been characterized in some detail and we named this system as "system 1". These families are as follows: ABA (Agaricus bisporus agglutinin), Amaranthin, CRA (chitinase-related agglutinin), Cyanovirin, EEA (Euonymus europaeus agglutinin), GNA (Galanthus nivalis agglutinin), Hevein, Jacalins, Legume lectin, LysM (lysin motif), Nictaba and Ricin_B families. However, the classification system was based on the available plant lectin information and animal lectins were not used to explore lectin-like members in the plant genomes.

Rapid progress has been achieved in genome sequencing with the great achievement in new sequencing technologies [8,9]. Both Arabidopsis and rice genomes have been completely sequenced [10-13] as model plants for dicot and monocot plants, respectively. Currently, soybean genome has also been completely sequenced (Soybean Genome Project, DoE Joint Genome Institute, http://www.phytozome.net/soybean). Up to now, genomes from 110 eukaryotes, 844 bacterial and 63 archaeal have been completely sequenced and published and the sequencing for 1028 eukaryotes, 2606 bacterial and 96 archaeal genomes are in progress based on the genome online database V 2.0 ([14]; http://www.genomesonline. org/gold.cgi, June 8, 2009). All these data provide us additional information to further analyze the lectin superfamily in their molecular evolution, classification and biological functions. However, limited data has been reported on the genome-wide characterization and molecular evolution of this superfamily in plants. As a result, little is known on the outline of all lectin genes in a completely sequenced plant genome and no new classification system has been proposed on the basis of the whole genome sequence information.

On the other hand, another major question that one may concern is on the biological functions of plant lectins. Many reviews or books have summarized the possible functions of plant lectins [4-6,15-18]. However, no definitive answers have been given. Generally, plant lectins have both internal and external activities [17]. The former refers to the functions acting within the plants during various developmental processes such as interactions with storage proteins or enzymes [17]. The latter includes the roles of lectins in response to various biotic and abiotic stresses. Evidence has shown the insecticidal activity of lectins against a spectrum of insects [19-24]. Some of lectin genes could be used for improving plant tolerance/resistance to various insects by transgenic technology [22,25-33]. However, such a desired effect in crop protection was not observed in some cases [34-36]. The protection functions of lectins against other biotic stresses were also reported including fungi [37-42] and virus [43,44]. Plant lectins are not only assumed to be part of the defense system $[3,45]$, they have been also implicated as playing an important role in mediating recognition and specificity in the symbiosis with root nodule bacteria [46-49]. Besides biotic stresses, plant lectins may also play roles in abiotic stresses [50]. Reports have shown that several lectin genes exhibit differential expression abundance under various abiotic stresses including temperature shock, drought and high salinity stresses [51-56].

Since limited data is available on the genome-wide analysis of lectin genes, we do not know how many members of this family in a genome are involved in biotic and abiotic stress-related biological processes and how these genes have been expanded or evolved with such functions. In this report, we first identified and characterized all lectin genes encoded by the soybean, rice and Arabidopsis genomes. We then proposed a new classification system on the basis of protein domain structures and phylogenetic analyses. We also evaluated their expansion mechanisms and evolutionary history by investigating their duplication and/or transposition history. Subsequently, we examined their expression by full-length cDNA, Expression Sequence Tag (EST), microarray and Massively Parallel Signature Sequencing (MPSS [57]) datasets. Finally, we investigated their expression divergence under various stresses to further annotate their biological functions. Our analyses advance the understanding of plant lectin genes as being involved in lineage-specific expansion, and that they function in biotic and abiotic stress-related developmental processes. We also identified putative new lectin genes which were not be experimentally detected at present in plant genomes and provided a new outline of the plant lectin gene superfamily.

\section{Results and Discussion}

Genome-wide identification of the lectin superfamily in soybean, rice and Arabidopsis

To survey lectin genes in legume plants, the soybean (Glycine $\max$ ) genome was selected as it has been 
completely sequenced. To better understand their expansion history and expression divergence, two other genomes were also selected for comparative analyses including rice (model plant for monocot) and Arabidopsis (model plant for dicot) genomes. We have used both BLAST and Hidden Markov model (HMM) searches (Methods) to identify lectin members presented in these genomes. After multiple cycles of searches, total of 349 , 339 and 204 putative lectin genes have been detected in soybean, rice and Arabidopsis, respectively. These members were then subjected to the Pfam ([58]; http://pfam. sanger.ac.uk/) and SMART ([59]; http://smart.embl-heidelberg.de/) databases to confirm the presence of corresponding domains. The analysis revealed some members with incomplete domain structures, which have been confirmed by both domain searches and manual check. These members contain no typical domain structure and have no expression evidence with the characters of pseudogenes. Due to the low feasibility of phylogenetic analyses by integrating these partial fragments, we removed these members from our analyses although we may under-estimate the rate of gene duplication. Thus, our analyses reveal that soybean, rice and Arabidopsis genomes encode total of 309, 267 and 199 members of lectin superfamilies (Figure 1A). Their locus name, physical position and annotated protein sequences were deposited in the Additional file 1 (soybean), 2 (rice) and 3 (Arabidopsis).

\section{A new classification system of the lectin superfamily in higher plants}

To classify these members, domain sequences from all members in each genome were aligned together and were then submitted to phylogenetic tree construction (Methods). The analyses show that all 3 organisms have 12 families of lectins (Figure 1B). They are named according to their domain description in the Pfam database, i.e., the B_lectin, Lectin_legB, Jacalin, Phloem, Lectin_C, Chitin_bind_1, Ricin_B_Lectin, Gal_lectin, Gal_binding_Lectin, Calreticulin, EEA and LysM families. In most cases, each family has a Pfam domain ID as shown in Figure 1A. However, no domain ID has been detected for the phloem and EEA families. The phloem domain was first structurally identified by Dinant et al. (2003) [60] with 4 conserved motifis and is characterized by a high frequency of charged residues and seven conserved Trp residues although phloem lectins were described in the seventies. Similarly, the EUL (Euonymus lectin) domain in the EEA family was recently identified $[7,61]$ although the family members were described more than 20 years ago [62]. Among the total 12 identified families, both B_lectin and Lectin_legB are the largest families for soybean and rice. However, in Arabidopsis, the largest one is the Jacalin family followed by Lectin_legB, B_lectin and Phloem families (Figure 1A). The smallest families contain only one or two members including Lectin_C, Ricin_B_Lectin and EEA families (Figure 1).

Based on the phylogenetic analyses of all genomewidely identified lectin genes in three organisms, we have proposed a new classification system. In this new system, each family contains members from a single carbohydrate binding-related domain. Compared with the classification system 1 [7], 8 families, including B-lectin, Lectin_legB, Jacalin, Chitin_bind_1, Ricin_B_Lectin, EEA, LysM and Phloem, have been found to match their corresponding families each other. Their coordinates are GNA, Legume lectin, Jacalins, Hevein, Ricin_B, EEA, LysM and Nitaba lectin families, respectively (Figure 2). No lectin member was identified in both rice and Arabidopsis genomes that was classified into the remaining 4 families including Cyanovirin, ABA, Amaranthin and CRA, which were reported by Van Damme et al (2008) [7]. The result was confirmed by our searches and the soybean genome may also lack lectins from these families (Figure 2). Thus, these families may be species-specific.

On the other hand, we also compared our new system with the classification system 2 as described in the website http://www.cermav.cnrs.fr/lectines/. Among the 6 classes of lectins in this system, 5 of them including $\alpha-$ D-mannose-specific plant lectin, Legume lectin, $\beta$-prism plant lectin, Agglutinin with hevein domain and $\beta$-trefoil lectin have been detected to match their corresponding families including B-lectin, Lectin_legB, Jacalin, Chitin_bind_1 and Ricin_B_lectin classes in our new system (Figure 2). Similarly, the class "Cyanovirin-N homolog" members have not been detected in our new system since they are mainly from fungi and bacteria. Furthermore, based on our taxonomic coverage analyses by the InterPro database [63], these 12 families are ubiquitous in higher plants while only limited species could be detected with the four families identified by the system 1 including Cyanovirin, ABA, Amaranthin and CRA. Thus, our new system can be used for the general lectin classification in higher plants and can not be used for species-specific lectins.

\section{Genome-wide identification reveals new classes of lectin families in soybean, rice and Arabidopsis}

Interestingly, we have detected four more families including Calreticulin, Gal_binding_lectin, Gal_lectin and Lectin_C, which are not detected in the two classification systems (Figure 2). They were usually detected in animals. However, the Calreticulin, Gal_binding_lectin and Gal_lectin families were also previously identified as putative plant lectins [64]. To our knowledge, no experimental data has been reported to confirm these 


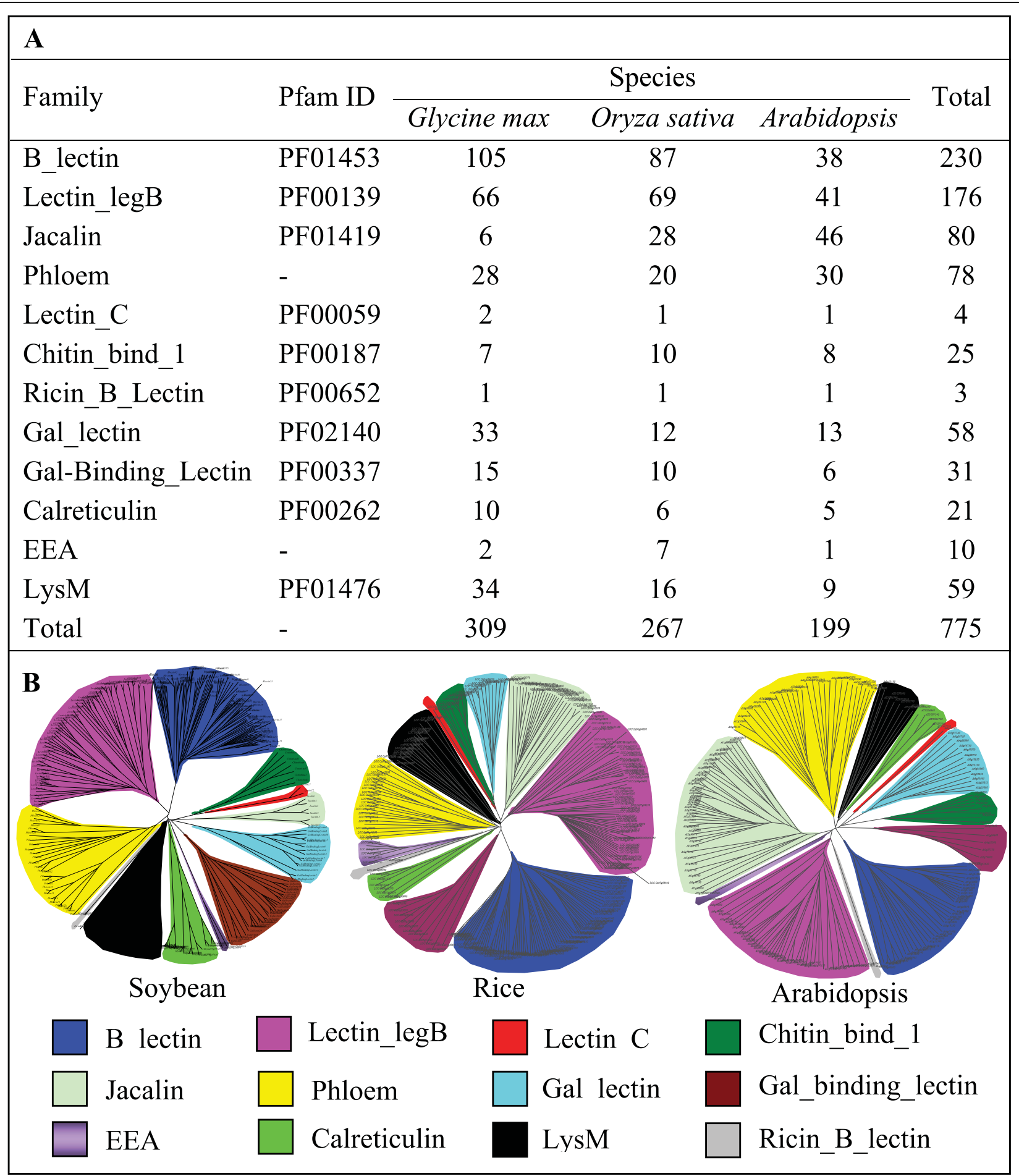

Figure 1 Genome-wide identification of lectin superfamily members and their classification. (A) All lectin members from 12 different lectin family in soybean, rice and Arabidopsis genomes. (B) Phylogenetic analysis of all lectin members in three different genomes. 

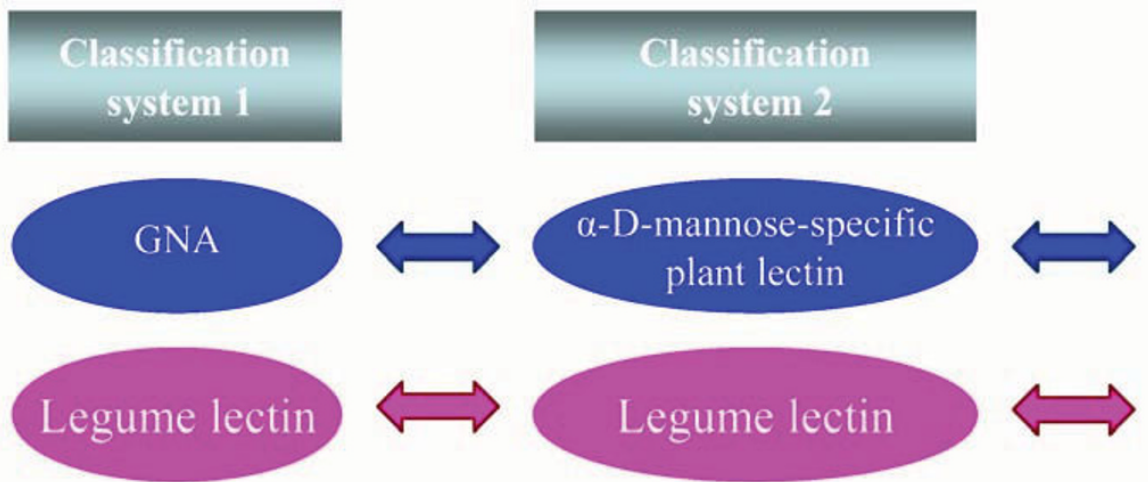

\section{Jacalins}
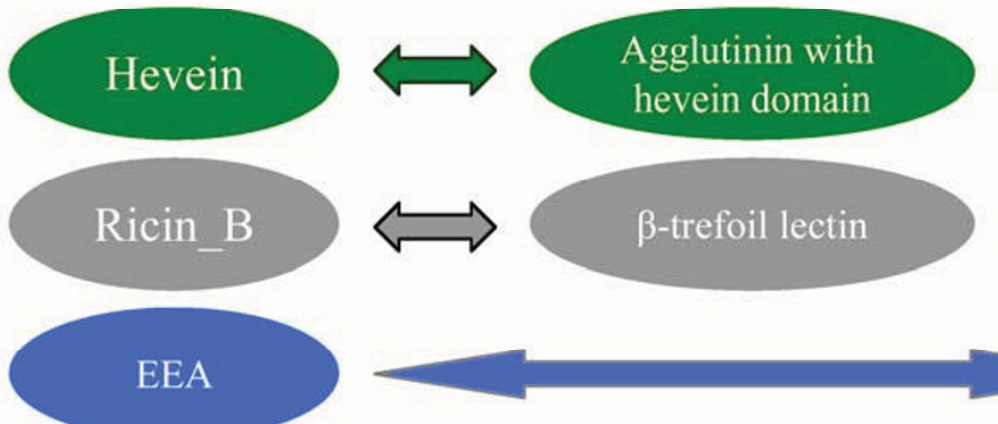

Agglutinin with hevein domain
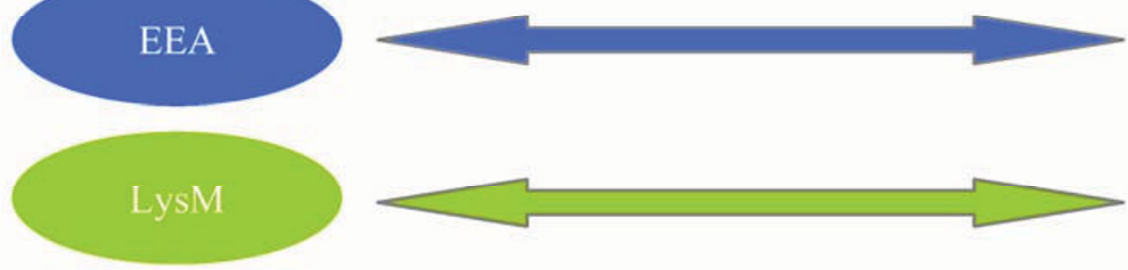

\section{Nictaba}
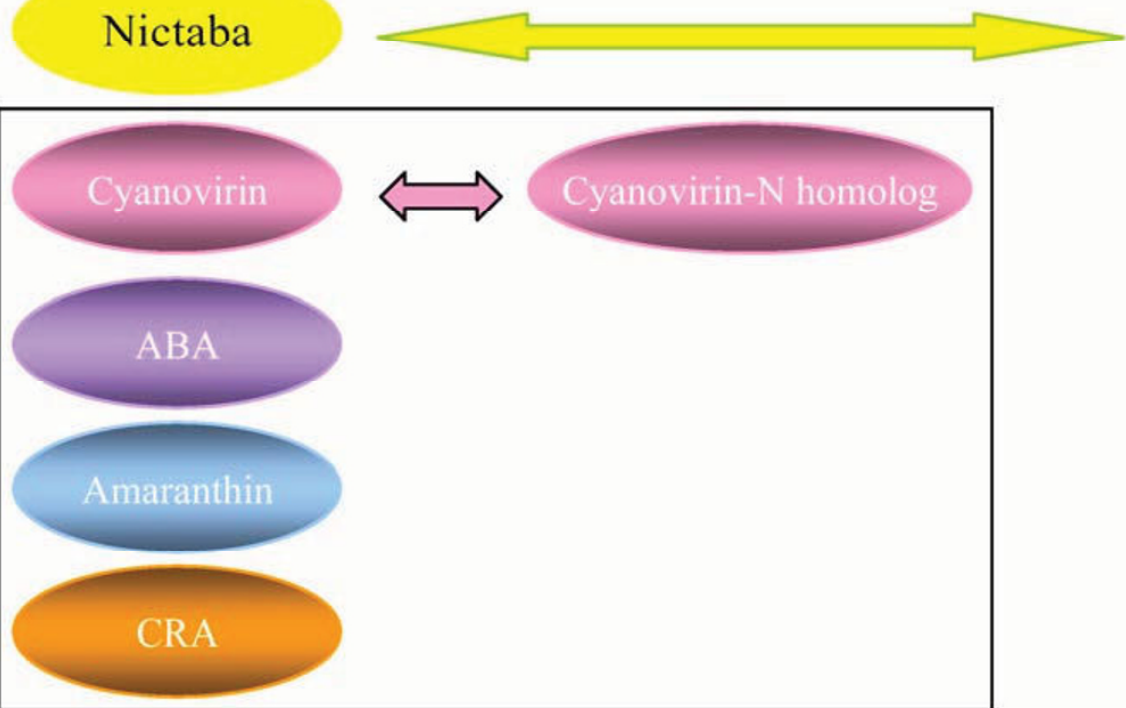
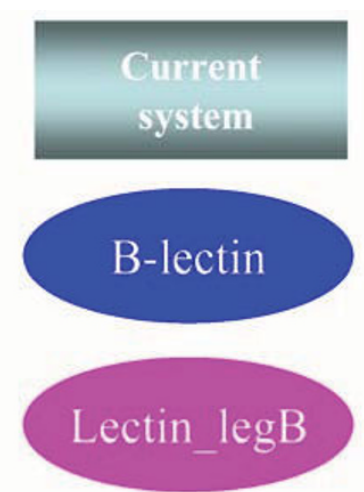

\section{Lectin $\operatorname{legB}$}

\section{Jacalin}
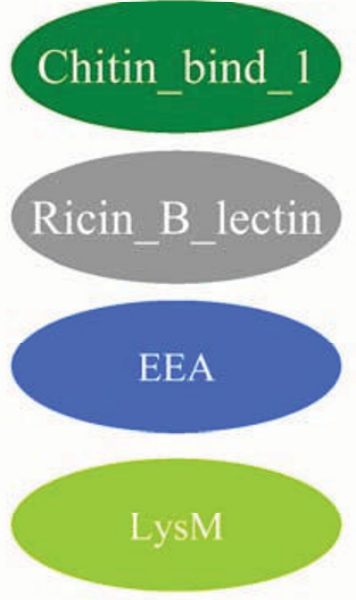

\section{Phloem}

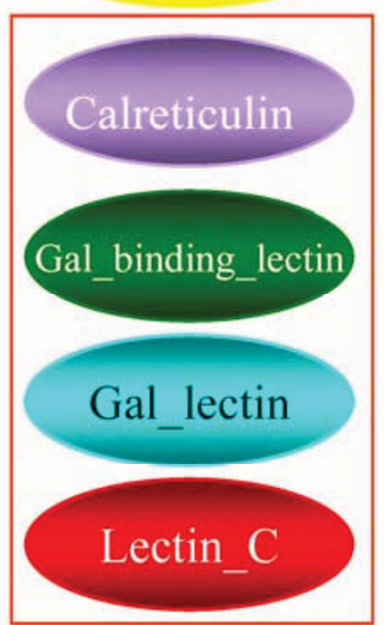

Figure 2 Comparison of the new classification system with two other systems. Classification system 1 is based on the description by Van Damme et al., (2008) [7]. The system 2 was based on 3D structures of lectins as described in the website: http://www.cermav.cnrs.fr/lectines/. The lectin families with no detectable member in soybean, rice and Arabidopsis were indicated by the rectangle with black lines and newly identified lectin families in the new classification system were framed by the rectangle with red lines. 
members as plant lectins. For the Calreticulin family, many members have been identified in plants [65]. However, no evidence shows their lectin activities although the family has been regarded as one of animal lectin groups [66]. The Lectin_C family is known as Stype lectins in animals and fungi. We have detected 2 members of the lectin_C family lectins in soybean and one member in both rice and Arabidopsis (Figure 1). Expression evidence is from EST for 2 soybean members and from full-length cDNAs for rice and Arabidopsis members, suggesting their presence in plants. Moreover, domain amino acid sequence alignments showed that these 4 Lectin_C domains from plants have at least 30\% sequence identities when compared with the most closely related domains from animals, demonstrating their possible function as C-type lectins.

Both the Gal_binding_lectin and Gal_lectin families are known as S-type lectins. For these two families, expression evidence was from EST for most of soybean members and from full-length cDNAs for both rice and Arabidopsis. The fact demonstrates the presence of these two domains in plants. However, their domain amino acid sequences share low identities (around $30 \%)$ when compared with the most closely related domains from animals. Thus, their functions as lectins should be demonstrated by testing their activities. We have randomly selected one of these newly identified lectin members for further analyses. This gene was named as LOC_Os03g06940 and contains two domains including both Glyco_hydro_35 and Gal_lectin (Figure $3 \mathrm{~A})$. The cDNA sequences from different domain regions were cloned into the expression vector pGEX$6 \mathrm{p}$. The GST fusion proteins were expressed in the Escherichia coli BL21 (Figure 3B). The recombinant protein extracts were used for detecting lectin activities by hemagglutination testing (Figure 3C-F). This method has been widely used for testing the lectin activity [55,67]. Our data show that the Gal_lectin domain indeed exhibits the agglutination activity whereas the Glyco_hydro_35 domain has no this function. The data suggest that this should be a new lectin identified in plants although its carbohydrate-binding specificity is not yet determined.

On the other hand, some of these four families of newly identified lectins contain other domains. Thus, many of them may be annotated as other proteins. For example, most of Gal_lectin or Gal-Binding lectin family members have been annotated as $\beta$-galactosidase or galactosyltransferase since these members contain Glyco_hydro_35 or Galactosyl_T domain, respectively. These domain combinations are also observed in bacteria, nematodes and higher animals. Therefore, they can be regarded as chimerolectins if their sugar binding properties can be experimentally validated.
Different families show difference in their expansion and large-scale expansions occurred after the divergence from their ancestors

Different lectin families exhibited differential expansions and as a result, plants have evolved into different sizes of lectin families. To infer the patterns of gene family expansions, we aligned the domain sequences of all members of each family from three organisms. The alignments were used to generate the phylogenetic trees and one of them is shown in Figure 4A, which was constructed with B-lectin domain sequences. The phylogenetic tree was then broken down into ancestral units, which were clades that were present before the divergence of these organisms according to the method described by Shiu et al (2004) [68]. The nodes of the most recent common ancestor (MRCA) were labeled with solid red circles between soybean and Arabidopsis and with black circles among 3 analyzed organisms (Figure $4 \mathrm{~A}$ ). We found that there were 9 ancestral units among 105 soybean and 38 Arabidopsis B-lectin members; however, only 5 MRCAs have been detected among total of 230 B-lectin family members from these three organisms (Figure 4A). The result indicated that the ancestral organism contained small family of B-lectin members and suggested that the large scale of expansions occurred after the divergence from their ancestors. A similar method was used for searching the lectin members of the ancestral organism for the remaining 8 families of lectins. The analysis showed that the ancestral organism between two dicot plants or among these three organisms also contained small numbers of lectin families (Figure 4B). Furthermore, we have also found several species-specific sub-family members for all three organisms (Figure 4A). All these results confirmed that the large scale of expansions occurred after the divergence from their common ancestors.

\section{Tandem and segmental duplications represent the major mechanism of lectin family expansion}

Based on the genome-scale duplication data in Arabidopsis and rice [69,70], one ancestral gene in the MRCA of Arabidopsis and rice may give birth to four and two novel genes in Arabidopsis and rice, respectively [71]. Thus, maximal 20 Arabidopsis and 10 rice B-lectin genes could be born on the basis of 5 members in the MRCA between these two species. However, they have much more numbers of lectin genes, suggesting that other mechanisms, such as tandem, segmental duplication and/or retroposition must have also contributed to the expansion of the lectin gene super family.

To investigate the contribution of tandem duplication to the expansion of lectin genes, we examined the chromosomal distribution of members in each family of all three organisms. Such analyses show that many genes 


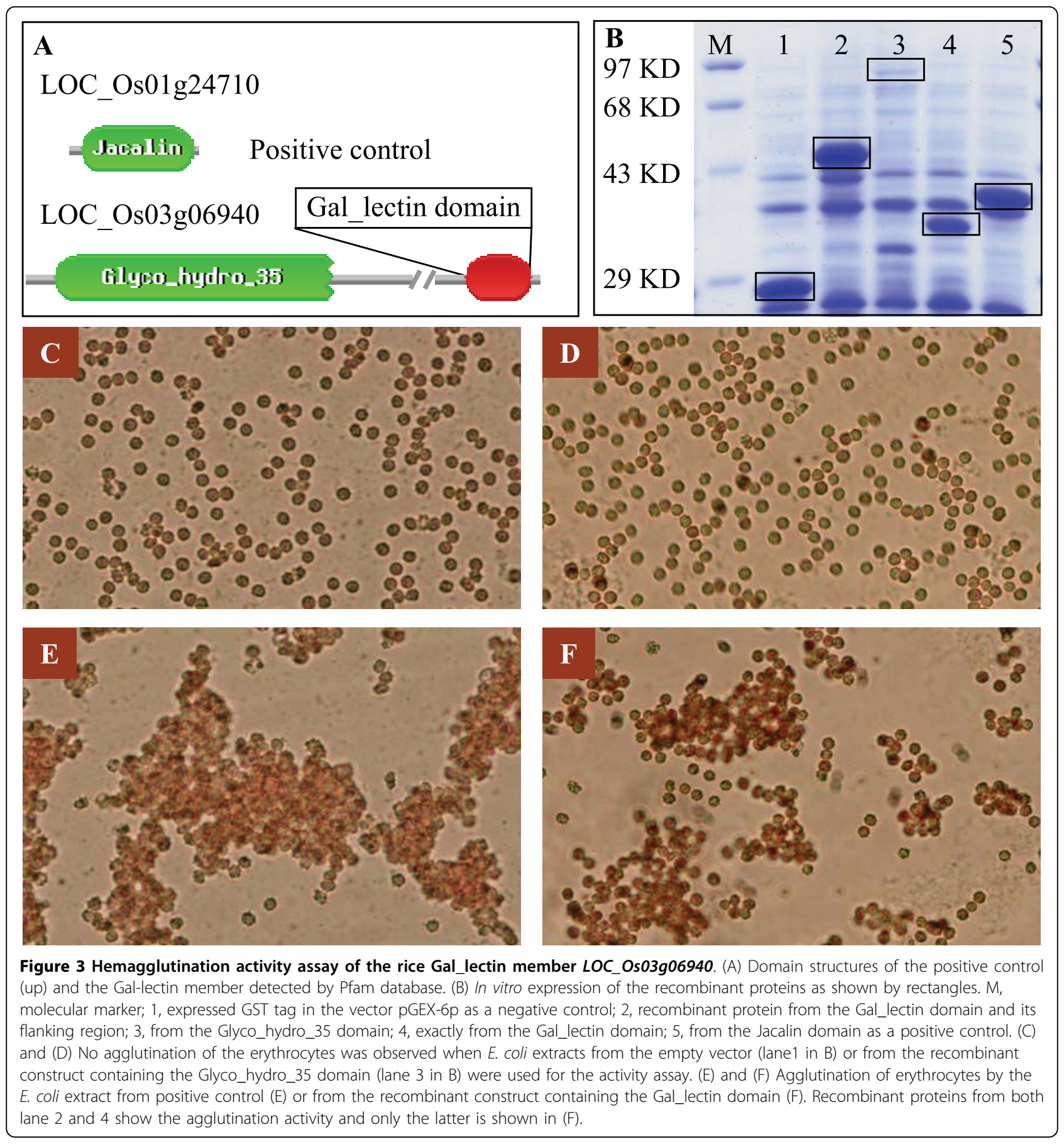

are clustered together according to the criterion as described in Methods section, suggesting that they were the results of tandem duplication. Totally, we have detected 131 (43\%), 140 (55\%) and 110 (551\%) lectin genes being involving in tandemly duplicated events in soybean, rice and Arabidopsis, respectively (Figure 5). On the other hand, we also genome-widely identified segmental duplications in soybean, rice and Arabidopsis genomes and then searched the duplication blocks that contain lectin genes. In this case, tandemly arrayed genes were treated as a single gene copy. We have detected total of 71 segmental blocks and their duplicated blocks with the same family of lectin genes in soybean (Additional file 4_sheet1). These genes were from total of 11 different families. One of the families is the Lectin_C and only one member was detected in both rice and Arabidopsis. However, two members were detected in soybean, which was due to the segmental 


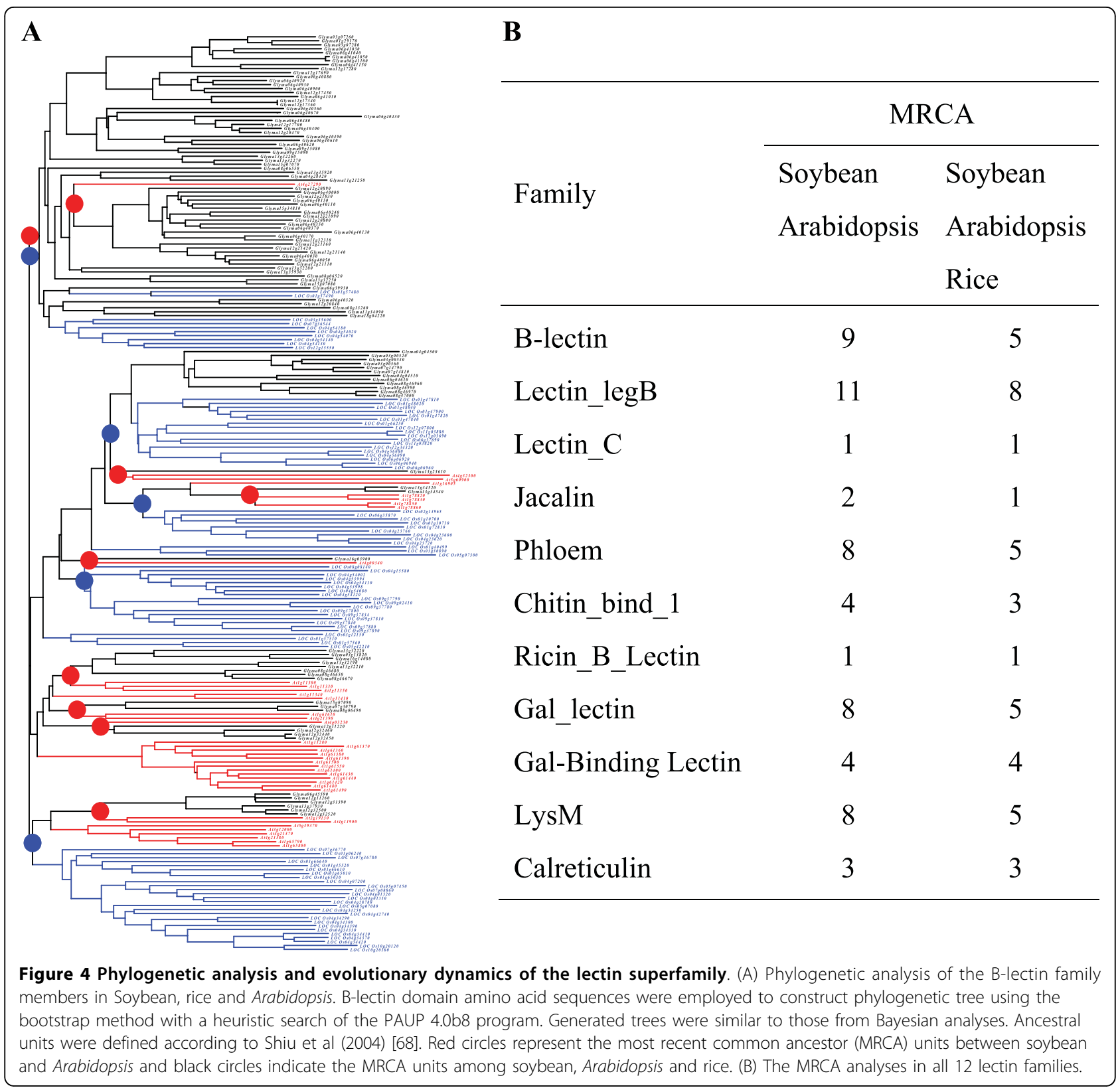

duplication as shown in the Additional file 4_sheet1. Similarly, we have 19 and 15 segmental and their duplicated blocks with lectin genes in rice and Arabidopsis, respectively (Additional file 4_sheet 2 and 3). In summary, we have detected total of 181 (59\%), 105 (40\%) and $85(43 \%)$ lectin genes being involving in segmentally duplicated events in soybean, rice and Arabidopsis, respectively (Figure 5). These data suggested that both tandem and segmental duplications play a major role in lectin gene expansions. Further investigation showed that some tandemly duplicated genes were also within segmentally duplicated regions with overlaps between these two duplications. Figure 5 summarizes the contributions of tandem and segmental duplications to the expansions of various lectin gene families in three different organisms. Generally, the highest contribution rate was observed in soybean with up to $84 \%$ of lectin genes were involved in tandem and/or segmental duplications and the remaining $16 \%$ of lectin genes were from other mechanisms. In both rice and Arabidopsis, similar results were observed with around $28 \%$ and $34 \%$ of lectin genes were from other mechanisms in general (Figure 5). However, the contributions of tandem and segmental duplications to lectin expansions differ among different lectin families. For example, only 12$24 \%$ of B-lectin family members were from the other 


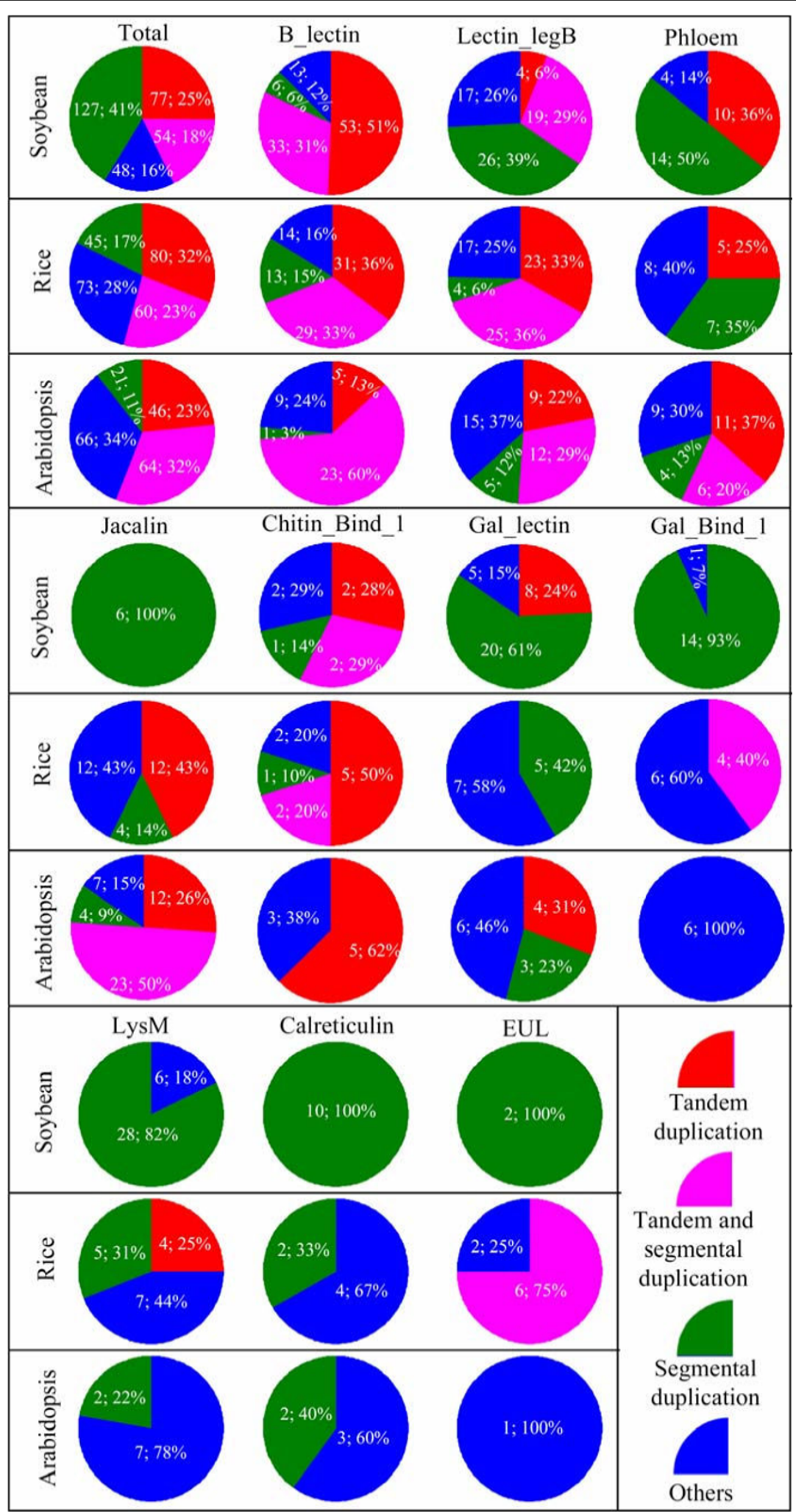

Figure 5 Expansion mechanisms of lectin genes. Pie diagrams were given to indicate the contributions of tandem (red), segmental (green) duplications and both of them (pink) as well as other mechanisms (blue) to the expansion of lectin superfamily in soybean, Arabidopsis and rice genomes. In each pie diagram, the number prior to the semicolon ";" indicates the total expanded members by different expansion mechanisms and its percentage is given following the semicolon. 
expansion mechanisms while the corresponding percentage has been up to $25-37 \%$ for Lectin_legB family (Figure 5). Furthermore, a same family also exhibits differences in their expansions among three organisms. For example, 14 of 15 Gal_Bind_1 family members were within segmentally duplicated regions in soybean whereas only 4 of 10 rice members have been involved in such events and no member in Arabidopsis has been born by tandem/segmental duplications (Figure 5). These facts may be regarded as one of reasons contributing to differential expansions of lectin members in different families of a same genome or in different genomes in a same family.

Besides the lectin superfamily, many other gene families also expanded themselves by tandem and/or segmental duplications in Arabidopsis and rice [72-74]. Since the soybean (Glycine max) genome sequencing data were released recently, limited data is available on the genome-wide identification of a gene family and its expansion history. We have genome-widely analyzed segmentally duplicated chromosome blocks in soybean. We found that many gene families in soybean also expanded themselves by segmental duplication such as AP2 domain encoding genes (estimated members: 345), WRKY transcription factors (estimated members: 176) and heavy-metal-associated domain encoding genes (estimated members: 127) and so on. For example, we have detected 55 out of 127 (43\%) heavy-metal-associated domain encoding genes being involved in segmental duplication.

\section{Species-specific expansion and rapid birth-and-death evolution of some lectin families}

We have observed that a same lectin family shows difference in their expansion among three species, exhibiting species-specific expansion. For example, the soybean genome encodes $105 \mathrm{~B}$-lectin genes whereas only 38 members were detected in Arabidopsis (Figure 1). To survey the possible mechanisms leading to species-specific expansion, we examined the contribution of tandem and/or segmental duplications to their expansion of these with at least two-fold difference in family members among 3 species including the B-lectin, Jacalin, Gal_lectin and Gal-Binding_lectin families. The investigation revealed multiple possible reasons responsible for the species-specific expansion. For example, deep expansion in the soybean B-lectin family is mainly due to the over expansion of tandem genes located on non-segmentally duplicated region (Figure 5). The Arabidopsis Jacalin family over-expanded themselves mainly by tandem and segmental mutual duplications (Figure 5). However, the major contribution of the species-specific expansion of the Gal_lectin and Gal_binding_1 lectin families is mainly due to the segmental duplication (Figure 5).

The evidence showed that monocot branched off from dicot plants 140-150 million years ago (MYA) [75-77]. Based on the divergence era and the estimation of the MRCA among soybean, rice and Arabidopsis as shown in Figure 4, the birth rate of B-lectin genes (counting only survival copies) is at least $13.3,10.9$ and 4.4 genes per 100 million years (MY) per ancestral gene in lineages leading to soybean, rice and Arabidopsis, respectively. The average rate of gene duplication is around 1 gene per 100 MY per ancestral gene in eukaryotes such as Homo sapiens, Mus musculus, Drosophila melanogaster, Caenorhabditis elegans, Saccharomyces cerevisiae and Arabidopsis thaliana [78]. Thus, these rates are significantly higher than the average one. Similarly, we have estimated the birth rates in other expanded families (Additional file 5). The analyses show that different families exhibit difference in their gene duplication rates. The highest rate was observed in the Jacalin family, where 30 genes per 100 million years in the lineage leading to Arabidopsis. The lowest rate was 0.3 , significantly lower than the average rate, and occurred in the Arabidopsis Gal-Bind_lectin and Calreticulin families. On the contrary, by comparing the expansion mechanisms (Figure 5) and gene birth rates (Additional file 5), we found that high gene birth rates are mainly due to tandem and/or segmental duplications. For these families, whose members being involving in both tandem and segmental duplications account for more than $50 \%$ of total identified lectins in all families and species, their gene birth rates were estimated at least 2 genes per 100 MY per ancestral gene. In addition, the rates of gene birth in multiple lectin gene families may be under-estimated. The actual numbers of duplicate genes that once existed in three species could be more than that we have detected as some duplicate copies might have already been deleted from the genome or been evolved into pseudogenes that are not included in this study. We have detected 86, 101 and 20 members from total of 12 families with partial domain sequences in soybean, rice and Arabidopsis, respectively. These partial sequences usually lack regions corresponding to sugar binding properties. Thus, they may be nonfunctional and could be regarded as pseudogenes. There seems to be a correlation between tandem duplication and pseudogenization since most of these members were from tandem duplication related expansion. On the other hand, some duplicated copies might be too divergent to be recognized now, which may also contribute to the under-estimation. Thus, higher rates of gene duplication should have occurred for some lectin families in these three species. 
Differential expansion patterns of tandem and segmental dual duplications among three organisms

Since the tandem duplication has been observed to largely contribute to the birth of new lectin genes, we further analyzed their expansion patterns. Domain amino acid sequences from the same tandem cluster were aligned first and were then used for the construction of their phylogentic tree, which were employed to analyze their expansion history. Based on such analyses, we found that parental genes were not always physically linked to their descendant genes and different expansion rates were observed for tandem genes in a same array. One of such examples was shown in Figure 6. In this example, we analyzed the patterns of tandem duplication in one of the largest tandem clusters in the soybean B-lectin family. We first investigated their expansion history by phylogenetic analyses (Figure 6A). The 19 tandem genes are in three clades, suggesting that this cluster was the results of three ancestral units, which may be evolved from ancient tandem duplication events. One of them contains only one gene, i.e. Glyma06g40130. No expansion was detected for this gene or its expanded genes have been lost during long evolutionary history. The second clade has 4 members whereas the third clade contains 14 members. On the basis of the phylogenetic tree, we deduced the hypothetical origins of 19 genes by tandem duplication (Figure $6 \mathrm{~B})$. The analyses showed that these genes were generated by at least 8 rounds of tandem duplication. After expansion, these genes were then not always inserted into the loci according to their physical orders. For example, the putative tandem pair of the Glyma06g40400 gene is Glyma06g40480 but not its physical neighbor Glyma06g40430. On the other hand, we found that most of tandem duplication occurred by a one-gene mode, i.e. only one gene was duplicated in a one tandem duplication event as shown in Figure 6. However, these cases were also observed that two or more genes in a cluster were duplicated through a single tandem duplication event (data not shown).

Based on our analyses on the expansion of the lectin superfamily by tandem and segmental duplications in three organisms (Figure 5), the evolution of considerable genes are related to both tandem and segmental

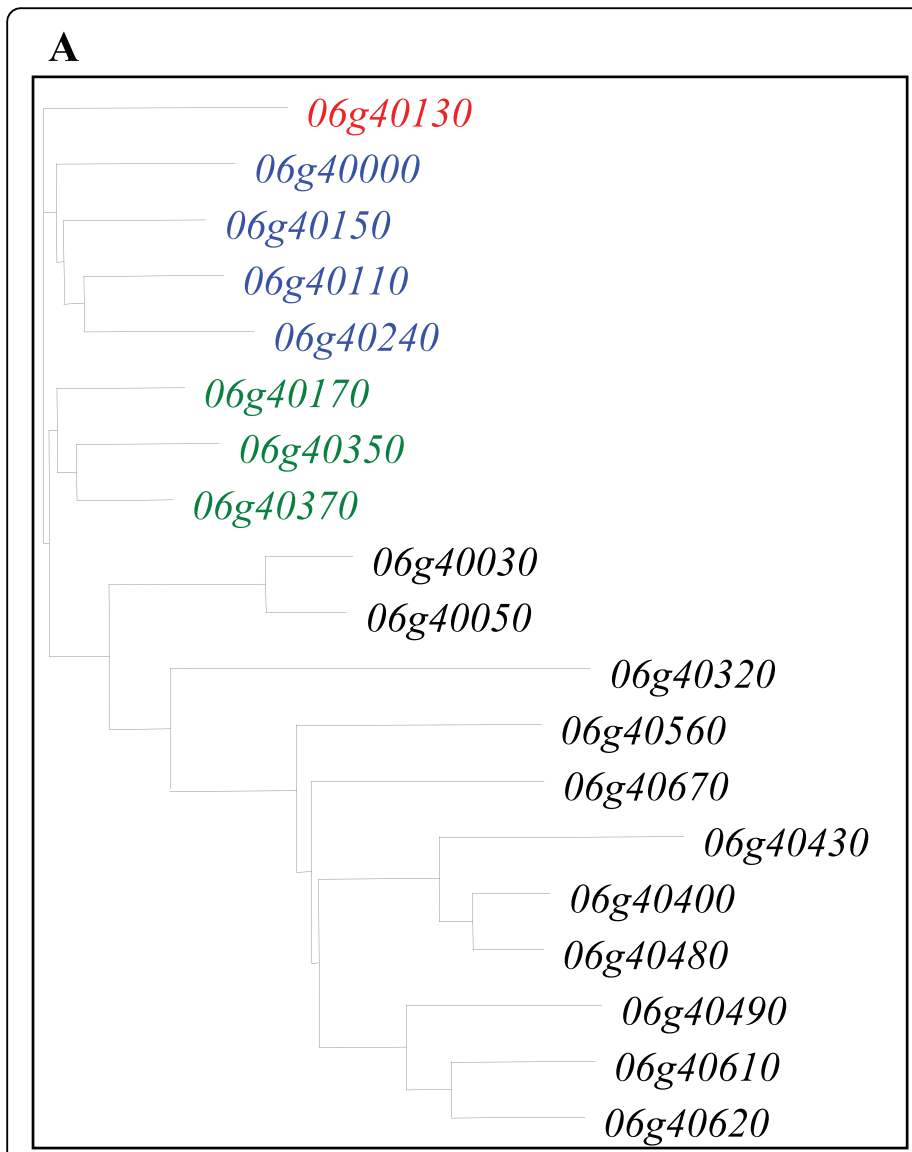

B

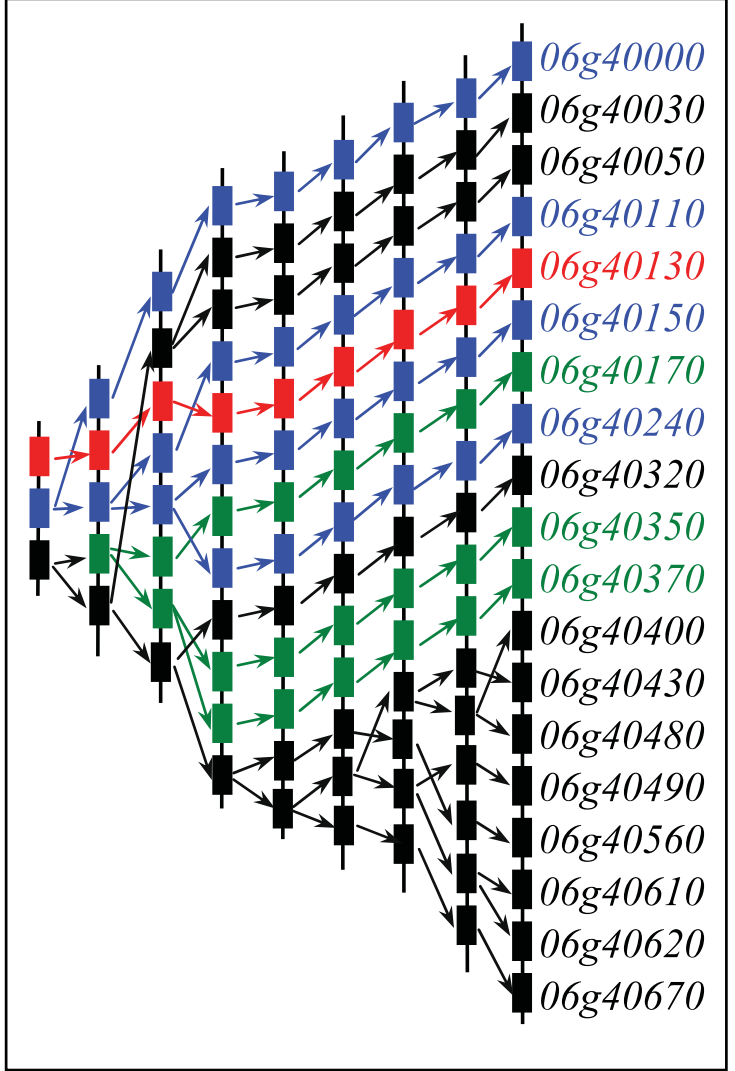

Figure 6 Expansion of one of the largest tandam clusters in B_lectin family by tandem duplications in soybean. (A) Phylogenetic relationships of 19 members from the tandem cluster. (B) Hypothetical origins of tandemly duplicated genes. The prefix "Glyma" of gene locus names have been omitted for convenience. 
duplications. To further investigate their contribution and patterns to the expansion of lectin members, segmental block pairs with at least 3 detectable tandemly arrayed genes were selected for more detail analyses. Totally, 6 pairs of segmental blocks with such criteria were detected. Three of them were from soybean including 2 B-lectin and 1 Lectin_legB pairs. Two of them were from Arabidopsis B-lectin and Jacalin families, respectively. The remaining one pair was from rice B-lectin family. Total of 6 phylogenetic trees were constructed for 6 pairs of segmentally and tandemly duplicated members. In most cases (5 of 6 pairs), a part of genes from the first tandem array are clustered together with another part of genes from the secondary tandem array. They exhibit tandem-segment mixed duplication model. These cases were observed in both dicot plants soybean and Arabidopsis as shown in Figure 7A and 7B. Such model of duplication may occur in two

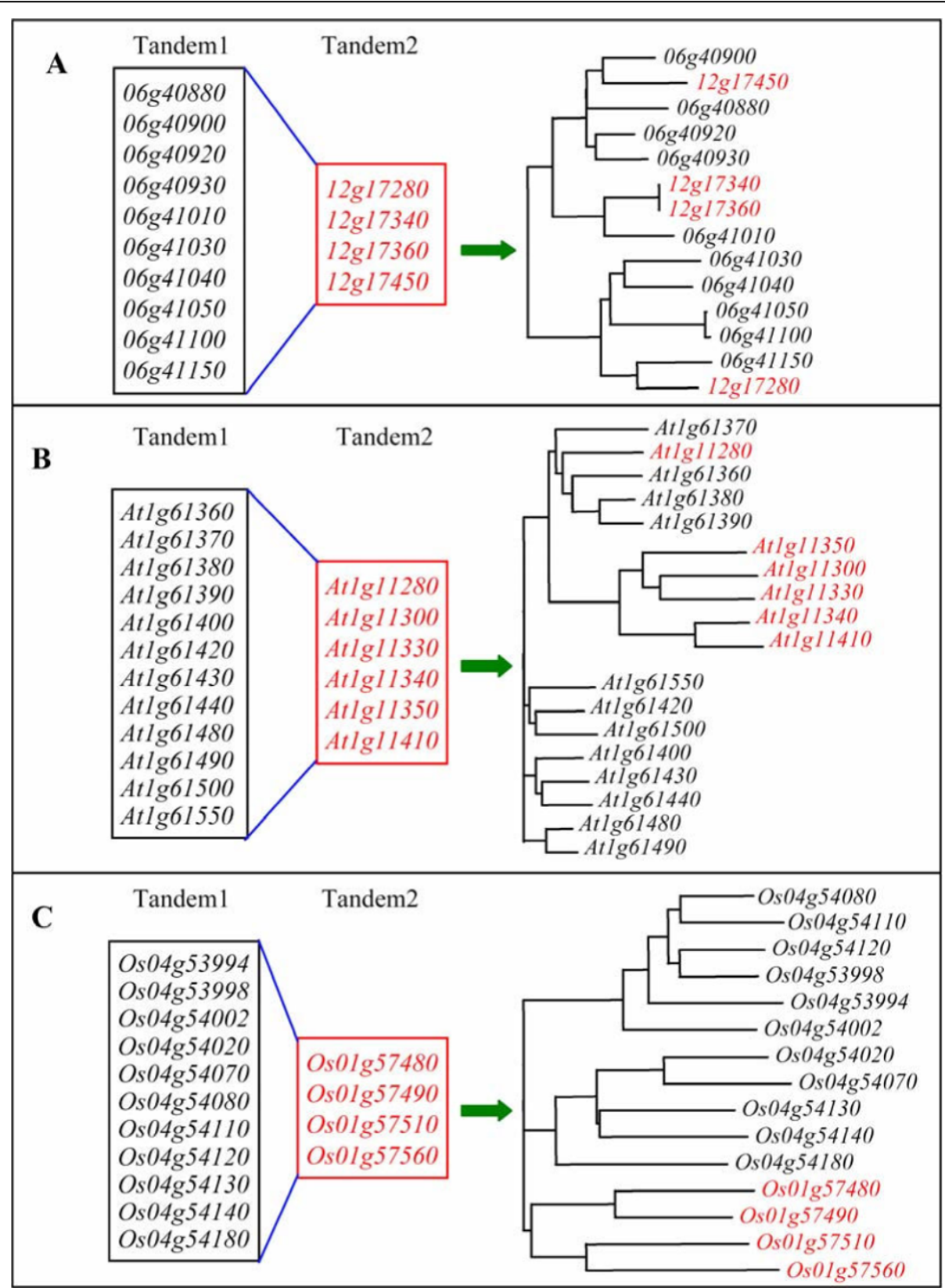

Figure 7 Differential expansion of lectin genes by both tandem and segmental duplications among soybean, Arabidopsis and rice. (A) and (B) Tandem-segment mixed duplication model in soybean and Arabidopsis, respectively. (C) Tandem-segment separated duplication model in rice. All analyzed example genes were from B-lectin family. 
ways. One of them is tandem-segment-tandem duplication. In this case, the expansion was by tandemly duplication first and was then by segmental duplication followed by tandem duplication. The second way is segment-tandem-segment duplication. However, in the monocot rice genome, lectin expansion was through another model as shown in Figure 7C. In this model, genes from a tandem array were clustered together and no clade was detected with members from both tandem arrays, exhibiting a tandem-segment separated duplication model. Based on the phylogenetic relationship of these tandemly and segmentally duplicated members, one reasonable explain is that they underwent segmental duplication first followed by tandem duplication.

\section{Limited but significant contribution of retrogenes to the birth of new lectin genes in both soybean and rice}

Since tandem and segmental duplications can not explain all the duplication events, we expect some of other mechanisms may also contribute to the expansion of the lectin superfamily. These include both retrotransposon and transposon mediated gene expansion, which has been reported in multiple species including rice and Arabidopsis [79-83]. By retrotransposition, a reversetranscribed mRNA was inserted into a new genomic position to form a retrogene. Such a retrogene is usually devoid of introns and with the presence of target site duplications and/or a poly (A) tract $[82,84]$. To survey the contribution of retrogenes to the expansion of the lectin superfamily, one-exon-containing lectin genes were used as query protein sequences for BLASTP searches against all two or more exon-containing lectins (Methods). The searches produced many candidate retrogenes in soybean and rice. We then manually identified these candidates by the presence of target site duplications (TSD) and/or a poly (A) tract. The analyses revealed 4 putative retrogenes in soybean and 7 in rice (Figure 8A). Some of them are still with 3 hallmarks of retrogenes. One example is the soybean retrogene Glyma08g46960 with both hallmarks including TSD and poly (A) tract; its parental gene Glyma03g00530 contains two exons (Figure 8B). On the other hand, not all identified retrogenes possess all three features, especially the poly (A) tract and short direct repeats $[82,84]$. These two hallmarks may no longer be recognized since they can be easily masked by base substitutions, insertions and/or deletions during a long evolutionary history [82]. Although very limited contribution has been detected by retrogenes (Figure $8 \mathrm{~A}$ ), they may play significant roles in the expansion of lectin genes. After the birth of a retrogene, it may further be expanded by tandem duplication. For example, the putative retrogene Glyma08g46960 was detected with tandem duplication followed by the birth of three new lectin genes including
Glyma08g46970, Glyma08g46990 and Glyma08g47000 (Figure $8 \mathrm{C}$ ). Moreover, no retrogene has been detected in the Arabidopsis lectin superfamily.

On the other hand, to investigate the contribution of DNA transposons to the expansion of lectin genes, a $100-110 \mathrm{~Kb}$ region including $50 \mathrm{~Kb}$ upstream and downstream sequences for each gene was achieved and was then used for the identification of major DNA transposons. We have analyzed class I mobile elements including Mutator-like transposable element (MULE), CACTA and $h A T$ as well as class II Helitron elements presented in these regions (Methods). In Arabidopsis, no above mentioned DNA transposon was detected to cover the lectin gene regions. However, we have identified considerable numbers of transposons presented in the 100-110 $\mathrm{Kb}$ regions in soybean. For example, 14 MULE-like, 3 CACTA and 20 Helitron elements have been detected and no $h A T$ element has been identified in soybean. However, most of these elements are located outside the corresponding lectin genes. Only 4 genes were identified within 4 Helitron elements. These genes include Glyma08g07040 (Lectin_legB), Glyma09g21970 (Gal_lectin), Glyma13g42210 (Chitin_bind_1) and Glyma20g02580 (Phloem). They are candidates to contribute to the expansion of lectin genes. Thus, DNA transposon elements have limited contribution to the expansion of the lectin superfamily in soybean. A similar situation was also observed in rice. In this organism, we have detected $6 M U L E$-like elements and all of them are located within lectin genes. Five of these elements are within introns of corresponding lectin genes including LOC_Os04g03579 (Lectin_legB), LOC_Os04g34410 (B_lectin), LOC_Os05g35360 (Gal_Lectin), LOC_Os11g39420 (Jacalin) and LOC_Os12g24170 (Gal_Lectin). The remaining one contributes the insertion of 6 exons of the lectin gene LOC_Os10g18400 (Gal_Lectin) and this $M U L E$-like element was named TI0006870 as described by Juretic et al (2005) [80]. In addition, the remaining elements including CACTA, hAT and Helitron have not been detected to contribute to the expansion of the lectin superfamily in rice.

\section{Expression profiling of the lectin superfamily in soybean, rice and Arabidopsis}

To survey the expression of all identified lectin genes, expression evidence was obtained from various expression databases as described in the Methods section. We identified a gene to be an expressed gene if a full-length cDNA, EST and/or microarry/RNA_Seq [85] could be available. Based on our investigation, more than $90 \%$ of lectin genes from all three organisms are regarded as expressed genes (Figure 9A). For soybean, only 10 lectin genes were experimentally detected to contain fulllength cDNAs and most expression evidence was from 


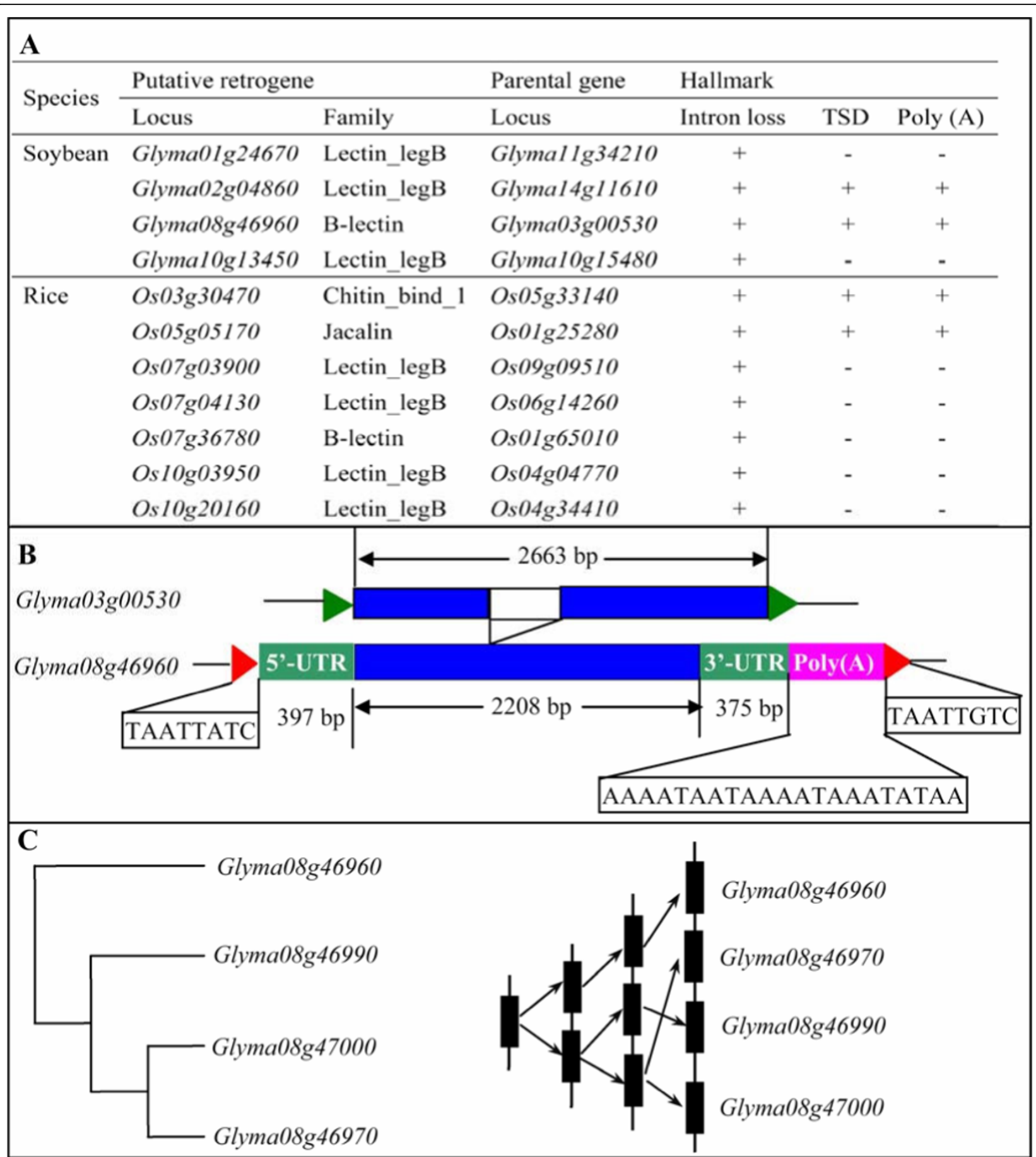

Figure 8 Retrogenes and their contributions to the expansion of lectin genes. (A) Retrogenes identified in soybean and rice genomes. (B) An example showing evolution of a lectin gene Glyma08g46960 by retrotranspositions from another lectin gene Glyma03g00530. The red arrowheads indicate the detected flanking direct repeats in an identified retrogene. The green arrowheads show the start (left) and end (right) positions of an annotated gene. The green boxes indicate the predicted 5'-UTR (left) and 3'-UTR (right) in a retrogene. The blue boxes indicate exons in both retrogenes and their host genes. The white boxes indicate an intron in the parental gene. (C) A retrogene mediated tandem duplication. 


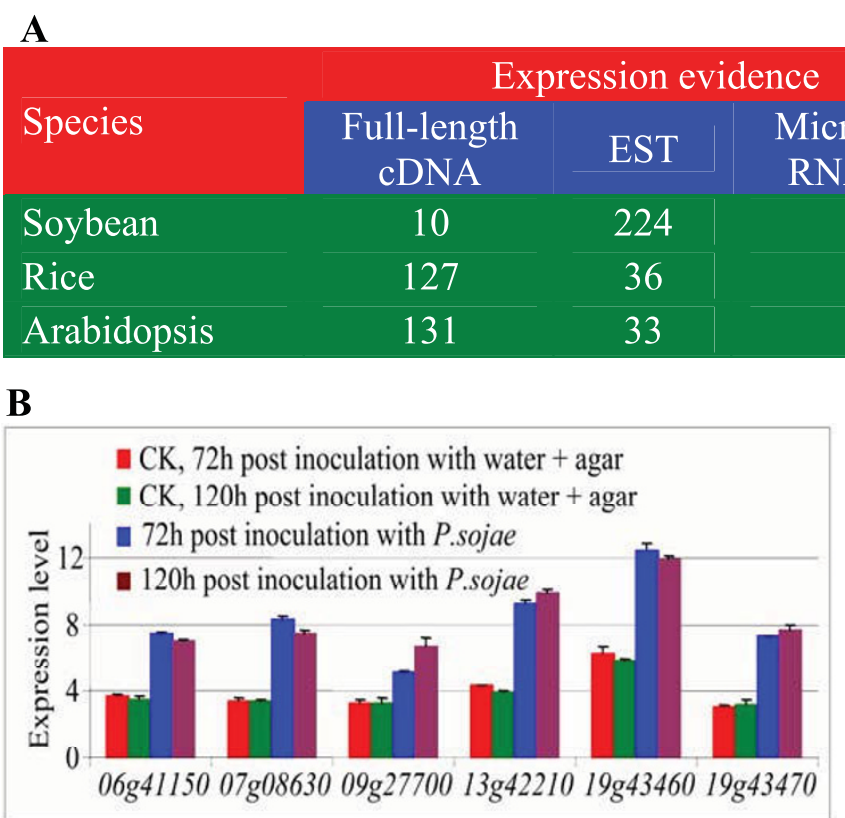

\section{Expression evidence}

\begin{tabular}{|c|c|c|c|c|}
\hline Species & Full-length & EST & Microarray/ & Expressed genes (\%) \\
\hline Soybean & $\begin{array}{c}\text { cDNA } \\
10\end{array}$ & 224 & $\underset{57}{\text { RNA_Seq }}$ & $291(94.2)$ \\
\hline Rice & 127 & 36 & 91 & $254(95.1)$ \\
\hline Arabidopsis & 131 & 33 & 33 & $197(99.0)$ \\
\hline
\end{tabular}

B

\section{D}

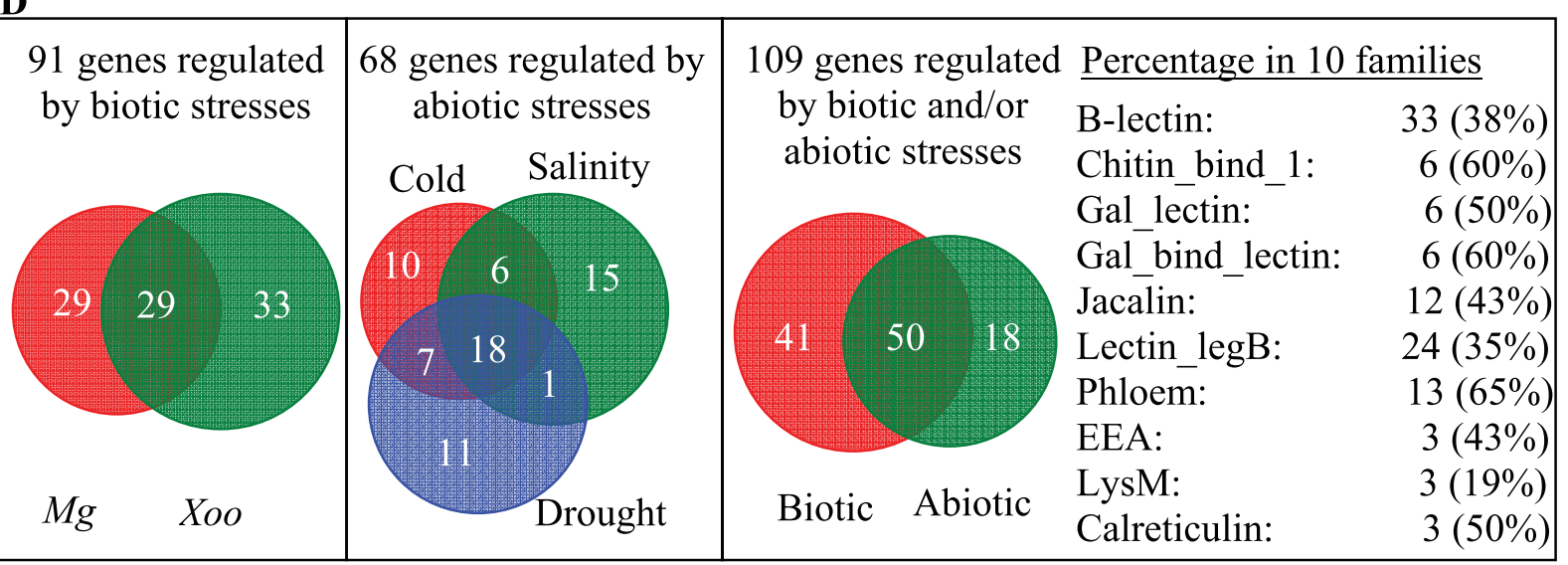

E

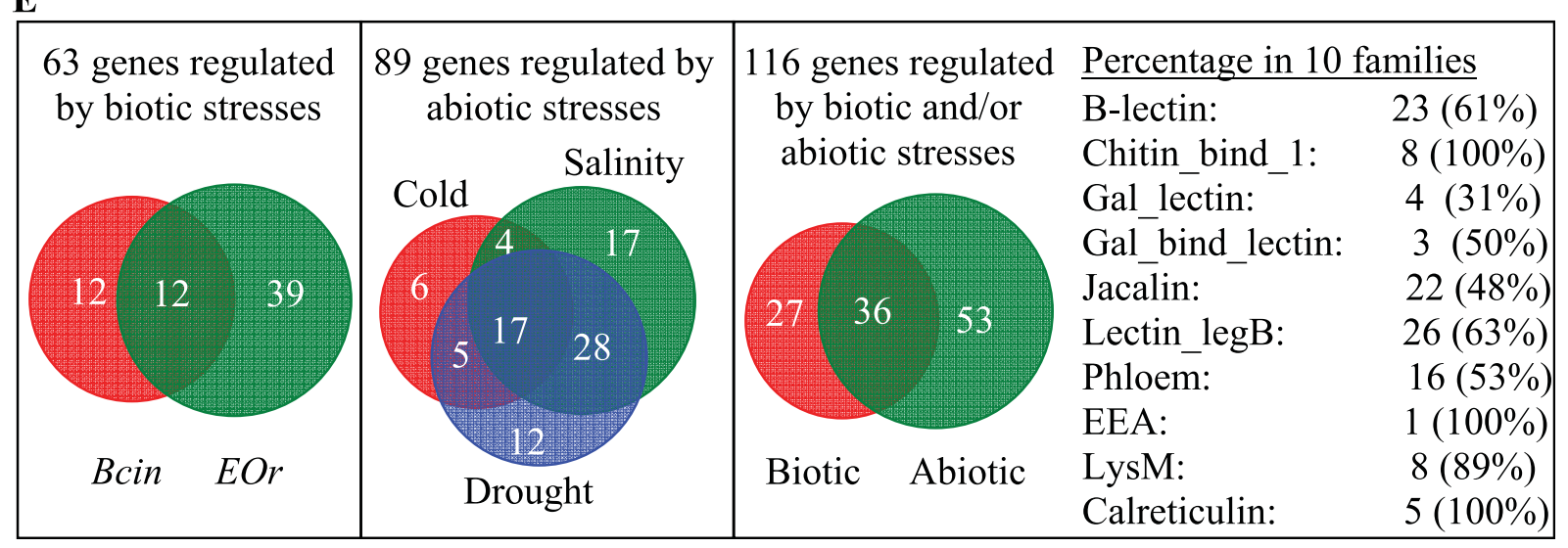

Figure 9 Expression profiles of lectin superfamilies in soybean, rice and Arabidopsis. (A) A general expression analysis showing the total expressed lectin genes in three organisms. (B) Five lectin genes showing up-regulation by the pathogen $P$. Sojae in soybean. The prefix "Glyma" in locus names was omitted for convenience. (C) Seven down-regulated and six up-regulated lectin genes by soybean cyst nematode. (D) and (E) Transcriptional profiles of lectin genes under various biotic and abiotic stresses rice and Arabidopsis, respectively. 
ESTs. In contrast, 127 of 267 (48\%) lectin genes have full-length cDNAs as expression evidence in rice and more than half of Arabidopsis lectin genes (131 of 199 or $66 \%$ ) have their corresponding full-length cDNAs.

To investigate the expression profiles under various biotic and abiotic stresses, microarray/MPSS data were achieved from various databases and statistic analyses were carried out (see Methods) to determine if the expression of a lectin gene is regulated by biotic/abiotic stresses. For soybean, only 71 lectin genes were probed in the Affymetrix microarray chips based on the annotation http://soybase.org/AffyChip/index.php. These genes are from 9 of 12 lectin families including B_lectin, Lectin_legB, Jacalin, Lectin_C, Chitin_bind_1, Gal_lectin, Gal_binding_Lectin, EEA and LysM. To analyze the expression profiles of these probed genes, microarray data were downloaded from Gene Expression Omnibus (GEO) DataSets [86] and Arrayexpress database [87] as described in the Methods section. We have analyzed the effects of both Phytophthora sojae and cyst nematode infections on the lectin gene expression. The analyses showed that 6 lectin genes exhibited up-regulation after the infection of the pathogen $P$. sojae (Figure 9B). These lectin genes include Glyma06g41150 (B-lectin), Glyma07g08630 (LysM), Glyma09g27700 (Lectin_legB) and three Chitin_bind_1 family genes: Glyma13g42210, Glyma19g43460 and Glyma19g43470. On the other hand, we have detected 16 lectin genes with changed expression by cyst nematode including 7 down-regulated and 9 up-regulated genes (Figure 9C). Among them, three genes were coregulated by both biotic stresses including Glyma09g27700, Glyma13g42210 and Glyma19g43460 (Figure 9A and 9B). Thus, total of 19 out of 71 lectin genes $(27 \%)$ have been detected to be involved in biotic stress-related signaling pathways.

On the other hand, we are also very interested in the soybean lectin genes related to legume-rhizobium symbiosis. We have found numbers of soybean-specific lectin family members based on the phylogenetic analysis. We are wondering whether some families of lectins involved in legume-rhizobium symbiosis are unique to soybean or are absent/non-functional in rice and Arabidopsis. A 36, 760 probe-containing microarray analysis showed that at least 73 lectin-related probes have been detected with Bradyrhizobium japonicum-regulated expression patterns [88]. These probes were from both soybean-specific and non-specific lectin genes. No enough evidence shows that soybean has evolved into some soybean-specific lectins specially for the legumerhizobium symbiosis. For example, the Lectin_legB family member Glyma02g18090 was up-regulated by the rhizobium. However, it is not soybean-specific lectin gene. Generally, our data have demonstrated that soybean lectin families have been involved in legumerhizobium symbiosis.

In rice and Arabidopsis, expression data of most lectin genes are available under various biotic and abiotic stresses. We have downloaded all expression data of rice lectin genes under biotic and abiotic stresses from rice MPSS database (Methods). Data analyses showed that total of 58 and 62 lectin genes were differentially expressed after infection by the fungus and bacterium pathogens Megnaporthe grisea $(M g)$ and Xanthomonas oryzae pv oryzae (Xoo), respectively, among which 29 genes were regulated by both pathogens (Figure 9D, Additional file 6). Thus, the expression abundance of total of 91 genes (34\%) was regulated by biotic stresses (Figure 9D). On the other hand, we have detected 68 genes (25\%) with differential expression under cold, drought and/or high salinity stresses, among which 18 genes were regulated by all of three abiotic stresses (Figure 9D, Additional file 6). Totally, we have detected 109 of 267 rice lectin genes (41\%) with differential abundance under biotic and/or abiotic stresses as 50 genes were regulated by both biotic and abiotic stresses (Figure 9D). The percentages of regulated genes in each family vary from $19 \%$ for the LysM to $65 \%$ for the Phloem families (Figure 9D).

In Arabidopsis, 63 of 199 lectin genes exhibited difference in their transcript abundance after the infection by the fungus and bacterium pathogens Botrytis cinerea (Bcin) or Erysiphe orontii (EOr), accounting for 32\% of the lectin superfamily members (Figure 9E, Additional file 7). Up to 89 genes (45\%) were regulated by cold, drought and/or high salinity stresses and this ratio is significantly higher than that in rice (Figure 9E, Additional file 7). Thus, total of 116 genes (58\%) underwent biotic/abiotic-stress regulation in their expression and each family showed difference in its response to both stresses with the percentages ranging from $31 \%$ for the Gal_lectin to $100 \%$ for the Chitin_bind_1, EEA and Calreticulin families (Figure 9E).

Besides the expression analyses under various stresses, we have also investigated the transcript profiling among different tissues to examine if the lectin superfamily has been involved in tissue specificity and functionality. In rice, we have examined the expression abundance in 13 different tissues. Our analysis showed that 7 out of 12 lectin families have been detected to contain genes with tissue-specific expression. The percentages of tissue-specific genes are $8.0 \%, 40.0 \%, 14.3 \%, 41.7 \%, 21.4 \%, 4.3 \%$ and $10.0 \%$ in the B-lectin, Chitin_binding_1, EEA, Gal_Lectin, Jacalin, Lectin_legB and Phloem families, respectively (Additional file 8). These lectin genes were preferentially expressed only in one or two tissues. In Arabidopsis, the transcript abundance was investigated among six different tissues including callus, germinating 
seedlings, inflorescence (mixed stages), leaves (21 day), root (21 day), silique (24-48 hour post-fertilization). Based on our analysis, only 4 out 12 lectin families contain genes with tissue-specific expression, significantly less than rice. These genes were from the B-lectin, Jacalin, Lectin_legB and Phloem families. The percentages of tissue-specific genes in these 4 families are $23.7 \%, 2.2 \%$, $9.8 \%$ and $16.7 \%$, respectively (Additional file 9 ). These data demonstrated that lectin genes not only play a role in specific stress conditions some lectin families but also have been involved in tissue specific biological functions.

\section{Expression divergence among tandemly and segmentally duplicated genes}

Our data show that both tandem and segmental duplications have significantly contributed to the expansion of the lectin superfamily and high percentage of lectin members exhibited differential expression patterns under various biotic and abiotic stresses. To explore the effect of both tandem and segmental duplication on the expression patterns, we have carried out a detail analyses on their expression divergence among tandemly or segmentally duplicated members.

In soybean, among analyzed 71 lectin genes, four members were from two tandem clusters. One of them exhibits expression divergence after infection by cyst nematode as shown in Figure 10A. On the other hand, we have also detected 8 segmentally duplicated blocks among 71 probed lectin genes in Affymetrix chips. Three blocks (38\%) exhibits expression divergence after infection by $P$. sojae or cyst nematode. For example, the gene Glyma12g17280 exhibits no difference in its expression after infection by $P$. sojae whereas its segmentally duplicated coordinate Glyma06g41150 was regulated by the pathogen (Figure 10B). Similar case was observed in another segmentally duplicated coordinates Glyma04g34620 and Glyma06g20030 (up-regulated by cyst nematode as shown in Figure 9C). However, for the third coordinates Glyma13g31250 and Glyma15g08100, both of them were down-regulated by cyst nematode and they exhibited difference in response to the infection time (Figure 10B).

In rice, we have analyzed the expression divergence of total of 42 tandem clusters and 24 segmental blocks. If the expression patterns of any members of a tandem cluster exhibit difference from any other members in the cluster under either any biotic or abiotic stresses, this cluster is regarded as a divergent cluster in their expression. A similar criterion has also been applied to the evaluation of expression divergence in segmental duplications. Based on the evaluation, we have identified 29 tandem clusters and 21 segmental blocks with differential expression under various biotic and abiotic stresses, accounting for $69 \%$ of total clusters and $88 \%$ of total segmental blocks, respectively (Figure 10C). Further analyses show that different lectin families exhibit significant difference in their expression divergence after tandem duplication, ranging from $40 \%$ for the Jacalin family to $100 \%$ for the Chitin_bind_1, Gal_binding and Phloem families (Figure 10C). On the other hand, for segmentally duplicated blocks, most of them show expression divergence for most of families (Figure 10C). However, the percentage may be over-estimated since the expression divergence from tandem duplication were also included if a tandem duplication occurred after segmental duplication.

In Arabidopsis, We have investigated total of 27 tandem clusters and 17 segmental blocks. Around 78\% of tandem clusters and $82 \%$ of segmental blocks have been observed with regulated expression patterns under either biotic or abiotic stresses (Figure 10D). In summary, expression data from soybean, rice and Arabidopsis demonstrate that tandem and segmental duplications significantly contribute to gene expression divergence under various biotic and abiotic stresses.

\section{Domain combinations, high percentages of expression divergence and biological functions of lectin genes}

Due to the presence of hololectins and chimerolectins, we have submitted all lectin protein sequences for other domain detection. The analyses revealed that many lectins also contained other domains besides the carbohydrate-binding domain. We have detected at least 5 other domains presented in at least $30 \%$ of corresponding family members. They are Kinase domain for B-lectin, Lectin_legB and Lectin_C families, F-box domain for phloem family, Glyco_hydro_19 domain for chitin_bind_1 family, Glyco_hydro_35 domain for Gal_lectin family and Galactosyl_T domain for Gal-Binding Lectin family (Table 1). Among them, more detail analyses have been carried out for the F-box-containing phloem lectins and they may play a role in nucleocytoplasmic protein degradation $[60,89]$. The presence of other domain suggests the more complicated functions and evolutions of plant lectins.

One may concern why the lectin families have evolved in these ways and how these duplicated genes are retained and whether there are any biological needs or advantages to drive their evolution. Domain combinations are the processes that generate new genes and functional divergences [90,91]. In this study, we have detected 5 domains presented in 7 families (Table 1). One of them is the kinase domain, which was presented in three families including B-lectin, Lectin_legB and Lectin_C. Here we focus on the B-lectin and Lectin_legB families since only one or two members were detected for the Lectin_C family in plants. For these two families, the combination with kinase domain did not occur in 
B
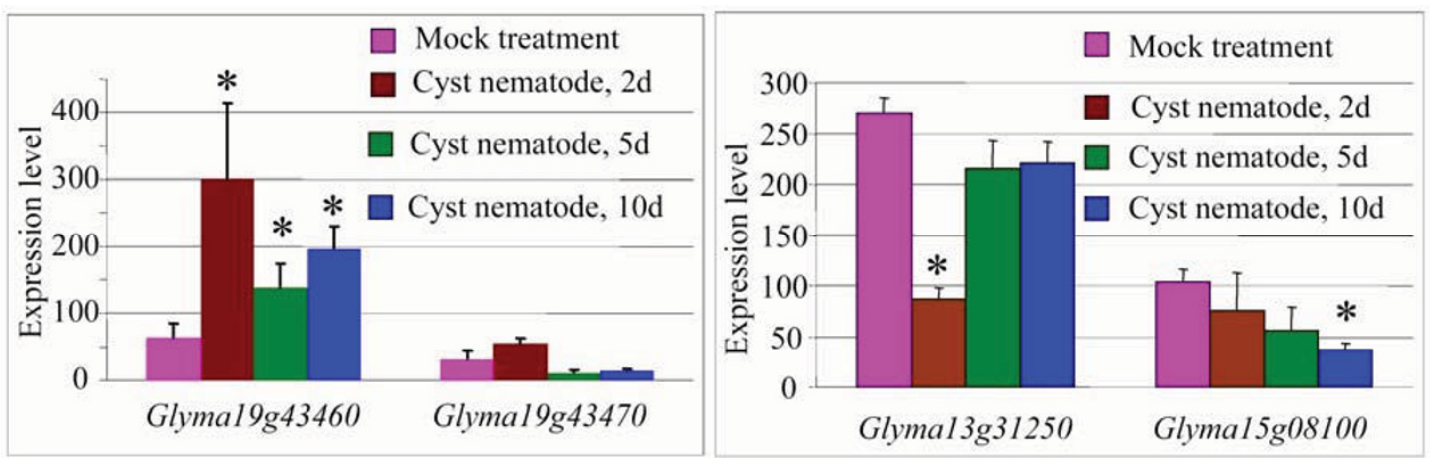

C

\begin{tabular}{|c|c|c|c|c|}
\hline \multirow[b]{2}{*}{ Family } & \multicolumn{2}{|c|}{ Tandem duplication } & \multicolumn{2}{|c|}{ Segmental duplication } \\
\hline & $\begin{array}{l}\text { tandem } \\
\text { Clusters }\end{array}$ & $\begin{array}{l}\text { Divergent clusters } \\
\text { in expression }(\%)\end{array}$ & $\begin{array}{l}\text { Segmental } \\
\text { blocks }\end{array}$ & $\begin{array}{c}\text { Divergent segments } \\
\text { in expression }(\%)\end{array}$ \\
\hline B-lectin & 16 & $10(63)$ & 5 & $4(80)$ \\
\hline Chitin_bind_1 & 3 & $3(100)$ & 1 & $1(100)$ \\
\hline Gal_lectin & 0 & 0 & 2 & $2(100)$ \\
\hline Gal_Binding_Lectin & 2 & $2(100)$ & 1 & $1(100)$ \\
\hline Lectin_legB & 11 & $10(91)$ & 3 & $3(100)$ \\
\hline Phloem & 1 & $1(100)$ & 5 & $5(100)$ \\
\hline Jacalin & 5 & $2(40)$ & 2 & $2(100)$ \\
\hline EUL & 2 & $1(50)$ & 1 & $1(100)$ \\
\hline LysM & 2 & 0 & 3 & $1(33)$ \\
\hline Calreticulin & 0 & 0 & 1 & $1(100)$ \\
\hline Total & 42 & $29(69)$ & 24 & $21(88)$ \\
\hline
\end{tabular}

\section{D}

\begin{tabular}{|c|c|c|c|c|}
\hline \multirow[b]{2}{*}{ Family } & \multicolumn{2}{|c|}{ Tandem duplication } & \multicolumn{2}{|c|}{ Segmental duplication } \\
\hline & $\begin{array}{l}\text { Tandem } \\
\text { Clusters }\end{array}$ & $\begin{array}{l}\text { Divergent clusters } \\
\text { in expression }(\%)\end{array}$ & $\begin{array}{l}\text { Segmental } \\
\text { blocks }\end{array}$ & $\begin{array}{l}\text { Divergent segments } \\
\text { in expression }(\%)\end{array}$ \\
\hline B-lectin & 5 & $4(80)$ & 2 & $2(100)$ \\
\hline Chitin_bind_1 & 1 & $1(100)$ & 0 & 0 \\
\hline Gal_lectin & 1 & $0(0)$ & 2 & $1(50)$ \\
\hline Jacalin & 9 & $5(56)$ & 4 & $2(50)$ \\
\hline Lectin_legB & 7 & $7(100)$ & 3 & $3(100)$ \\
\hline Phloem & 4 & $4(100)$ & 4 & $4(100)$ \\
\hline LysM & 0 & 0 & 1 & $1(100)$ \\
\hline Calreticulin & 0 & 0 & 1 & $1(100)$ \\
\hline Total & 27 & $21(78)$ & 17 & $14(82)$ \\
\hline
\end{tabular}

Figure 10 Expression divergence among tandemly and segmentally duplicated lectin genes in soybean, rice and Arabidopsis. (A) and (B) Examples of expression divergence under cyst nematode treatment after tandem (A) or segmental (B) duplications in soybean. (C) and (D) The effect of tandem and segmental duplications on gene expression divergence of different lectin families under abiotic and biotic stresses in rice and Arabidopsis, respectively. 
Table 1 Taxonomic coverage and domain combination of the lectin superfamily

\begin{tabular}{|c|c|c|c|c|c|}
\hline \multirow[b]{3}{*}{ Family } & \multirow[b]{3}{*}{ Taxonomic coverage } & \multicolumn{4}{|c|}{ Other domain $^{a}$} \\
\hline & & \multirow[b]{2}{*}{ Name } & \multicolumn{3}{|c|}{ Percentage (\%) } \\
\hline & & & Soybean & Rice & Arabidopsis \\
\hline B-lectin & Mainly in plants & Kinase & 90.5 & 92.0 & 78.9 \\
\hline Lectin_legB & Mainly in plants & & 72.7 & 87.0 & 85.4 \\
\hline Lectin_C & Mainly in animals & & 100.0 & 100.0 & 100.0 \\
\hline Jacalin & Plants, animals and microorganisms & - & - & - & - \\
\hline Phloem & Only in plants & F-box & 82.1 & 46.4 & 56.7 \\
\hline Chitin_bind_1 & Mainly in plants and fungi & Glyco_hydro_19 & 71.4 & 80.0 & 87.5 \\
\hline Ricin_B_Lectin & Plants, animals and microorganisms & - & - & - & - \\
\hline Gal_lectin & Mainly in animals & Glyco_hydro_35 & 100.0 & 100.0 & 69.2 \\
\hline Gal-Binding Lectin & Mainly in animals & Galactosyl_T & 100.0 & 100.0 & 100.0 \\
\hline Calreticulin & Plants and animals & - & - & - & - \\
\hline EEA & Mainly in plants & - & - & - & - \\
\hline LysM & Plants, animals and microorganisms & - & - & - & - \\
\hline
\end{tabular}

animals, bacteria and fungi, suggesting that the domain composition was established during the course of plant evolution. Phylogenetic analyses showed that most of these domains were from the receptor-like kinase (RLK)/Pelle family [68]. Interestingly, this family also underwent a rapid birth-and-death evolution in plants [68]. Thus, both lectin and kinase domains were maintained by according evolution.

We try to further elucidate the biological benefits to drive the expansion and retention of the lectin superfamily by surveying the effect of tandem and/or segmental duplications on the expression divergence under biotic and abiotic stresses. Previous reports have showed that tandemly duplicated genes tend to be involved in biotic and abiotic stresses $[72,83]$. Many of the RLK family members are B-lectin or Lectin_legB domaincontaining proteins in rice and Arabidopsis [68]. Interestingly, the expression data also support the importance of this family in stress response [92]. These results further confirmed the co-evolution of B-lectin/Lectin_legB and kinase domains. Our expression data suggest a link between biotic/abiotic stresses and tandem/segmental duplications in lectin families and also suggest that not only tandem but also segmental duplications of lectin genes may be regarded as drivers for plants to adapt various environmental stresses through duplication followed by expression divergence, thus, providing an explanation for why some of lectin families exhibit large expansion. Highly divergent expression profiles also demonstrate that each member of this gene superfamily may play specialized roles in a specific stress condition and function as a regulator of various environmental factors such as cold drought and high salinity stresses as well as biotic stresses. The detection of tissue- specifically expressed genes further demonstrated the comprehensive biological functions of this superfamily.

\section{Conclusions}

Our data show that higher plant genomes encode large numbers of lectin proteins. These proteins can be phylogenetically classified into 12 different families and four of them consist of recently identified plant lectin members. Further analyses show that some of lectin families exhibit species-specific expansion and rapid birth-and-death evolution. Tandem and segmental duplications have been regarded as the major mechanisms for lectin expansion. Our analyses also shows that lectin genes have been involved in biotic/abiotic stress regulations and tandem/ segmental duplications may be regarded as drivers for plants to adapt various environmental stresses through duplication followed by expression divergence. All in all, our studies provide a new outline of the plant lectin gene superfamily and advance the understanding of plant lectin genes in their evolution, expansion and biotic/abiotic stress-related biological functions.

\section{Methods}

\section{Databases, annotations and sequence retrieval}

Three different databases have been selected to retrieve all lectin genes encoded by the soybean, rice and Arabidopsis genomes. The annotated protein sequences from these three genomes have been downloaded from the following websites: http://www.phytozome.net/soybean for soybean (Glyma1.0), http://rice.plantbiology.msu.edu for rice (release 6) and http://www.Arabidopsis.org for Arabidopsis (TAIR8).

All lectin domains were achieved from both Pfam and EBI database http://www.ebi.ac.uk/. Key sequences of 
various domains were obtained from the Pfam databases. However, the key sequences of the phloem and EEA lectin domains were obtained from Dinant et al (2003) [60] and Van Damme et al (2008) [7], respectively, since no Pfam ID is available in the database. These key domain sequences from each lectin domain were aligned by ClustalX 2.0 [93] and were then used to generate HMM profiles for HMM searches with e-value cutoff of 1.0. After filtration by domain confirmation using both the Pfam and the SMART databases, sequences with full-length domain were used for BLAST searches to achieve more lectin sequences.

\section{Sequence alignment and phylogenetic analysis}

The DNASTAR program was used for the preliminary sequence manipulations. The sequence alignment was generated using ClustalX (Version 2.0) with manual adjustments using lectin domain sequences from various lectin families. The aligned amino acid sequences formed the basis for the phylogenetic analysis using the program Mac PAUP 4.0b8 (ppc) http://www.paup.csit. fsu.edu and MrBayes 3.1 [94] according to the description by Jiang and Ramachandran (2006) [95].

\section{Detection of duplication-related lectin genes}

Tandemly duplicated lectin genes in soybean, rice and Arabidopsis were identified by three criteria: (1) they are less than or equal to 10 genes apart; (2) they belong to the same lectin family; and (3) they are within $100 \mathrm{~kb}$ for Arabidopsis or $350 \mathrm{~kb}$ for both soybean and rice as suggested by Lehti-Shiu et al. (2009) [92].

The genome-wide identification of segmentally duplicated chromosome blocks has been carried out previously in soybean http://www.phytozome.net/soybean. php, rice [70,73] and Arabidopsis [96]. We examined the segmental duplicates by comparing positions of lectin genes with known duplicated chromosomal blocks. Since some of these investigations only dealt with relatively recent (for soybean) or ancient (for Arabidopsis) duplication events, we also compared the flanking regions (50 kb upstream and downstream) of the lectin gene pairs in these two species to identify the ancient (for soybean) or recent (for Arabidopsis) duplicated blocks according to the method [71].

\section{Detection of transposable element (TE)-related lectin genes}

To detect the contribution of class I TEs (retrotransposons) to the expansion of lectin gene families, possible retrogenes in the lectin superfamily were identified. Lectin genes encoded by single exon were subjected to BLASTP searches against all the remaining lectin protein sequences with two or more exon-containing coding sequences. Homologs were collected for further analysis while minimum $70 \%$ of queried protein coding regions were aligned with an E-value threshold at $10^{-8}$. We then selected candidate retrogenes based on the criteria [82].

To determine the contribution of class II TEs (DNA transposons) to the expansion of this superfamily, the flanking genomic sequences of the $50 \mathrm{~kb}$ upstream and downstream of lectin genes were used for the identification of 4 major transposon family members. These include mutator-like transposable element (MULE), hAT, CACTA and Helitron families.

We identified MULE members using similar methods as described by Jiang et al (2004) [79] and Juretic et al (2005) [80]. To identify the members of $h A T$ and CACTA DNA transposon families, we used two separate approaches including BLASTN and HMM searches as described by one of our previous reports [97].

\section{Processing of expression data under biotic and abiotic stresses as well as among various tissues in soybean, rice and Arabidopsis}

We obtained the expression evidence of a lectin gene by examining the availability of a full-length cDNA, EST or expressed microarray/RNA_seq tags in a lectin gene. The investigation was carried out by searching the following databases: http://www.phytozome.net/soybean. php for soybean, http://rice.plantbiology.msu.edu/ for rice and http://www.Arabidopsis.org/ for Arabidopsis.

The soybean expression data under the pathogen Phytophthora sojae was downloaded from the GEO DataSets [86] with accession number GSE7124. The microarray data after the infection by soybean cyst nematode were obtained from the Arrayexpress database [87] with accession number E-MEXP-808 [98]. Lectin genes with at least 2 -fold difference in their average expression signals under normal and stressed conditions were subjected to students't $t$-test to determine if the genes were significantly regulated by stresses. For rice, the expression data from the MPSS database [57] were used to analyze the transcriptional profiles of lectin genes under biotic and abiotic stresses as well as among different tissues. We have analyzed the effects of cold, drought and high salinity stresses as well as bacterium and fungus pathogens on the expression of lectin genes. Similar criteria have been employed to identify differentially expressed genes as described above for soybean. For Arabidopsis, the recently published expression data under biotic and abiotic stresses were downloaded and differentially expressed lectin genes were identify according to the description [99]. We used the Arabidopsis MPSS database [100] to investigate the tissuespecifically expressed genes. 


\section{In Vitro expression of a lectin gene and hemagglutination tests}

Since we have detected three new lectin families based on the genome-wide identification, one of the family members were randomly selected for the detection of the lectin activity. The cDNA sequence of the Gal_lectin family member LOC_OsO3g06940 with corresponding full-length cDNA (accession number: AK102192) was isolated by RT-PCR using rice total RNA as template. The cDNA sequence region corresponding to its Gal_lectin domain and the remaining region were separately subcloned into Escherichia coli expression vector pGEX-6P (GE Healthcare). One of the Jacalin family members $L O C_{-}$OsO1g24710 with known lectin activity [55] was used as positive control. A total of 6 $\mathrm{mL}$ of $E$. coli culture was collected by centrifuging at $3000 \mathrm{rpm}$ for $10 \mathrm{~min}$ at $4^{\circ} \mathrm{C}$. The collection was dissolved with $1 \times$ PBS buffer and was sonicated on ice in short bursts. The hemagglutination test was carried out by mixing $20 \mu \mathrm{l}$ sonicated culture extract with $20 \mu \mathrm{l} 2 \%$ suspension of rabbit red blood cells. Agglutination was assessed visually after $1 \mathrm{~h}$ at room temperature.

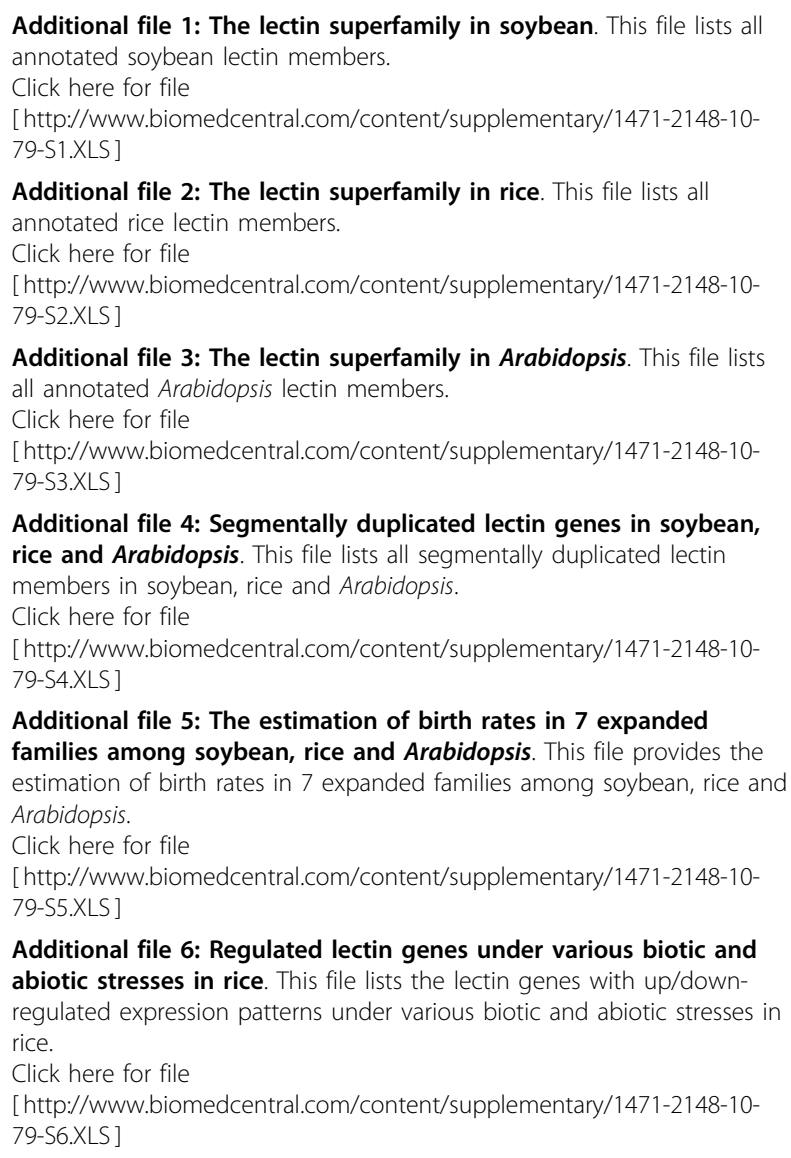

Additional file 7: Regulated lectin genes under various biotic and abiotic stresses in Arabidopsis. This file lists the lectin genes with up/ down-regulated expression patterns under various biotic and abiotic stresses in Arabidopsis.

Click here for file

[http://www.biomedcentral.com/content/supplementary/1471-2148-1079-S7.XLS ]

Additional file 8: Lectin genes with tissue-specific expression patterns in rice. This file lists the lectin genes with tissue-specific expression patterns in rice.

Click here for file

[http://www.biomedcentral.com/content/supplementary/1471-2148-1079-S8.XLS ]

Additional file 9: Lectin genes with tissue-specific expression patterns in Arabidopsis. This file lists the lectin genes with tissuespecific expression patterns in Arabidopsis.

Click here for file

[http://www.biomedcentral.com/content/supplementary/1471-2148-1079-S9.XLS ]

\section{Abbreviations}

ABA: Agaricus bisporus agglutinin; CRA: chitinase-related agglutinin; EEA: Euonymus europaeus agglutinin; EST: expression sequence tag; EUL: Euonymus lectin; GEO: gene expression omnibus; GNA: Galanthus nivalis agglutinin; HMM: hidden markov model; LysM: lysin motif; MPSS: massively parallel signature sequencing; MRCA: most recent common ancestor; MULE: Mutator-like transposable element; TE: transposable element; TSD: target site duplications

\section{Acknowledgements}

We thank Zheng Xiumin for the preliminary data processes. We also thank Subramanian Kabilan for providing rabbit red blood cells. The soybean sequence data were produced by the US Department of Energy Joint Genome Institute http://www.jgi.doe.gov/ in collaboration with the user community.

\section{Authors' contributions}

SR supervised the study. SYJ conceived of the study and carried out most of the work. ZM performed the hemagglutination activity assay. All authors read and approved the final manuscript.

Received: 27 August 2009 Accepted: 18 March 2010 Published: 18 March 2010

\section{References}

1. Lis $H$, Sharon N: Lectins: carbohydrate-specific proteins that mediate cellular recognition. Chem $\operatorname{Rev} 1998,98: 637-674$.

2. Vijayan M, Chandra N: Lectins. Curr Opin Struct Biol 1999, 9:707-714.

3. Peumans WJ, Van Damme EJM: Lectins as Plant Defense Proteins. Plant Physiol 1995, 109:347-352.

4. Sharon N: Lectins: past, present and future. Biochem Soc Trans 2008, 36:1457-1460

5. Van Damme EJM, Peumans WJ, Barre A, Rouge P: Plant lectins: a composite of several distinct families of structurally and evolutionally related proteins with diverse biological roles. Crystal Rev Plant Sci 1998, 17:575-692.

6. Van Damme EJM, Peumans WJ, Pusztai A, Bardocz S: Handbook of plant lectins: properties and biomedical applications. John Wiley \& Sons, Chichester, UK 1998.

7. Van Damme EJM, Lannoo N, Peumans WJ: Plant Lectins. Adv Botanical Res 2008, 48:107-209.

8. Mardis ER: Next-generation DNA sequencing methods. Annu Rev Genomics Hum Genet 2008, 9:387-402.

9. Lister R, Gregory BD, Ecker JR: Next is now: new technologies for sequencing of genomes, transcriptomes, and beyond. Curr Opin Plant Biol 2009, 12:107-118. 
10. The Arabidopsis Genome Initiative: Analysis of the genome sequence of the flowering plant Arabidopsis thaliana. Nature 2000, 408:796-815.

11. Goff SA, Ricke D, Lan TH, Presting G, Wang R, Dunn M, Glazebrook J, Sessions A, Oeller $P$, Varma $H$, et al: A draft sequence of the rice genome (Oryza sativa L. ssp. Japonica). Science 2002, 296:92-100.

12. Yu J, Hu S, Wang J, Wong GK, Li S, Liu B, Deng Y, Dai L, Zhou Y, Zhang X, et al: Draft Sequence of the Rice Genome (Oryza sativa L. ssp. Indica). Science 2002, 296:79-92.

13. International Rice Genome Sequencing Project: The map-based sequence of the rice genome. Nature 2005, 436:793-800.

14. Liolios K, Mavrommatis K, Tavernarakis N, Kyrpides NC: The genomes on line database (GOLD) in 2007: status of genomic and metagenomic projects and their associated metadata. Nucleic Acids Res 2008, 36: D475-D479.

15. Etzler ME: New insights into the functions of legume lectins. Trends Glycosci Glycotechnol 1998, 10:247-55.

16. Rudiger $H$, Rouge P: Structure and function of plant lectins. Carbohydrates in Europe 1998, 23:18-22.

17. Rudiger H, Gabius HJ: Plant lectins: occurrence, biochemistry, functions and applications. Glycoconj J 2001, 18:589-613.

18. Sharon N, Lis H: Lectins. Kluwer Academic Publishers, 22003.

19. Fitches E, Woodhouse SD, Edwards JP, Gatehouse JA: In vitro and in vivo binding of snowdrop (Galanthus nivalis agglutinin; GNA) and jackbean (Canavalia ensiformis; Con A) lectins within tomato moth (Lacanobia oleracea) larvae; mechanisms of insecticidal action. J Insect Physiol 2001, 47:777-787.

20. Gatehouse AMR, Down RE, Powell KS, Sauvion N, Rahbe Y, Newell CA Merryweather A, Hamilton WDO, Gatehouse JA: Transgenic potato plants with enhanced resistance to the peach-potato aphid Myzus persicae. Entomol Exp Appl 1996, 34:295-307.

21. Wang W, Hause B, Peumans WJ, Smagghe G, Mackie A, Fraser R, van Damme EJ: The Tn antigen-specific lectin from ground ivy is an insecticidal protein with an unusual physiology. Plant Physiol 2003, 132:1322-1334

22. Nagadhara D, Ramesh S, Pasalu IC, Rao YK, Sarma NP, Reddy VD, Rao KV Transgenic rice plants expressing the snowdrop lectin gene (gna) exhibit high-level resistance to the whitebacked planthopper (Sogatella furcifera). Theor Appl Genet 2004, 109:1399-1405.

23. Sadeghi A, Smagghe G, Broeders S, Hernalsteens JP, De Greve H, Peumans WJ, Van Damme EJM: Ectopically expressed leaf and bulb lectins from garlic (Allium sativum L.) protect transgenic tobacco plants against cotton leafworm (Spodoptera littoralis). Transgenic Res 2008, 17:9-18

24. Subramanyam S, Smith DF, Clemens JC, Webb MA, Sardesai N, Williams CE: Functional characterization of HFR1, a high-mannose N-Glycan-specific wheat lectin induced by hessian fly Larvae. Plant Physiol 2008, 147:1412-1426.

25. Hilder VA, Powell KS, Gatehouse AMR, Gatehouse JA, Gatehouse LN, Shi Y, Hamilton WDO, Merryweather A, Newell CA, Timans JC, et al: Expression of snowdrop lectin in transgenic tobacco plants results in added protection against aphids. Transgenic Res 1995, 4:18-25.

26. Gatehouse AMR, Davison GM, Newell CA, Merryweather A, Hamilton WDO, Burgess EPJ, Gilbert RJC, Gatehouse JA: Transgenic potato plants with enhanced resistance to the tomato moth Lacanobia oleracea: Growth room trials. Mol Breeding 1997, 3:49-63.

27. Rao KV, Rathore KS, Hodges TK, Fu X, Stoger E, Sudhakar D, Williams S, Christou $P$, Bharati M, Bown DP, et al: Expression of snowdrop lectin (GNA) in transgenic rice plants confers resistance to rice brown planthopper. Plant J 1998, 15:469-477.

28. Tinjuangjun P, Loc NT, Gatehouse AMR, Gatehouse JA, Christou P. Enhanced insect resistance in Thai rice varieties generated by particle bombardment. Mol Breeding 2000, 6:391-399.

29. Magbool SB, Riazuddin S, Loc NT, Gatehouse AMR, Gatehouse JA, Christou P. Expression of multiple insecticidal genes confers broad resistance against a range of different rice pests. Mol Breeding 2001, 7:85-93.

30. Nagadhara D, Ramesh S, Pasalu IC, Rao YK, Krishnaiah NV, Sarma NP, Bown DP, Gatehouse JA, Reddy VD, Rao KV: Transgenic Indica rice resistant to sap-sucking insects. Plant Biotechnol J 2003, 1:231-240.
31. Pham Trung N, Fitches E, Gatehouse JA: A fusion protein containing a lepidopteran-specific toxin from the South Indian red scorpion (Mesobuthus tamulus) and snowdrop lectin shows oral toxicity to target insects. BMC Biotechnol 2006, 6:18.

32. Saha P, Majumder P, Dutta I, Ray T, Roy SC, Das S: Transgenic rice expressing Allium sativum leaf lectin with enhanced resistance against sap-sucking insect pests. Planta 2006, 223:1329-1343.

33. Yarasi B, Sadumpati $V$, Immanni CP, Vudem DR, Khareedu VR: Transgenic rice expressing Allium sativum leaf agglutinin (ASAL) exhibits high-level resistance against major sap-sucking pests. BMC Plant Biol 2008, 8:102.

34. Birch ANE, Geoghegan IE, Majerus MEN, McNicol JW, Hackett CA, Gatehouse AMR, Gatehouse JA: Tri-trophic interaction involving pest aphids, predatory 2-spot ladybirds and transgenic potatoes expressing snowdrop lectin for aphid resistance. Mol Breeding 1999, 5:75-83.

35. Bell HA, Fitches EC, Down RE, Marris GC, Edwards JP, Gatehouse JA, Gatehouse AMR: The effect of snowdrop lectin (GNA) delivered via artificial diet and transgenic plants on Eulophus pennicornis (Hymenoptera: Eulophidae), a parasitoid of the tomato month Lacanobia oleracea (Lepidoptera; Noctuidae). J Insect Physiol 1999, 45:983-991.

36. Bell HA, Fitches EC, Marris GC, Bell J, Edwards JP, Gatehouse JA, Gatehouse AMR: Transgenic GNA expressing potato plants augment the beneficial biocontrol of Lacanobia oleracea (Lepidoptera; Noctuidae) by the parasitoid Eulophus pennicornis (Hymenoptera; Eulophida). Transgen Res 2001, 10:35-42

37. Ponstein AS, Bres-Vloemans SA, Sela-Buurlage MB, Elzen van den PJ, Melchers LS, Cornelissen BJ: A novel pathogen- and wound-inducible tobacco (Nicotiana tabacum) protein with antifungal activity. Plant Physiol 1994, 104:109-118

38. Wang X, Bauw G, Van Damme EJ, Peumans WJ, Chen ZL, Van Montagu M, Angenon G, Dillen W: Gastrodianin-like mannose-binding proteins: a novel class of plant proteins with antifungal properties. Plant J 2001, 25:651-661.

39. Koo JC, Chun HJ, Park HC, Kim MC, Koo YD, Koo SC, Ok HM, Park SJ, Lee SH, Yun DJ, et al: Over-expression of a seed specific hevein-like antimicrobial peptide from Pharbitis nil enhances resistance to a fungal pathogen in transgenic tobacco plants. Plant Mol Biol 2002, 50:441-452.

40. Chen X, Shang J, Chen D, Lei C, Zou Y, Zhai W, Liu G, Xu J, Ling Z, Cao G, et al: A B-lectin receptor kinase gene conferring rice blast resistance. Plant J 2006, 46:794-804.

41. Chen J, Liu B, Ji N, Zhou J, Bian HJ, Li CY, Chen F, Bao JK: A novel sialic acid-specific lectin from Phaseolus coccineus seeds with potent antineoplastic and antifungal activities. Phytomedicine 2009, 16:352-360.

42. Baker RL, Brown RL, Chen ZY, Cleveland TE, Fakhoury AM: A maize lectinlike protein with antifungal activity against Aspergillus flavus. J Food Prot 2009, 72:120-127.

43. Saha P, Dasgupta I, Das S: A novel approach for developing resistance in rice against phloem limited viruses by antagonizing the phloem feeding hemipteran vectors. Plant Mol Biol 2006, 62:735-752.

44. Keyaerts E, Vijgen L, Pannecouque C, Van Damme E, Peumans W, Egberink H, Balzarini J, Van Ranst M: Plant lectins are potent inhibitors of coronaviruses by interfering with two targets in the viral replication cycle. Antiviral Res 2007, 75:179-187.

45. Chrispeels MJ, Raikhel NV: Lectins, lectin genes, and their role in plant defense. Plant Cell 1991, 3:1-9.

46. Diaz CL, Melchers LS, Hooykass PJJ, Lugtenberg BJJ, Kijne JW: Root lectin as a determinant of host-plant specificity in the Rhizobium-legume symbiosis. Nature 1989, 338:579-581.

47. Brewin NJ, Kardailsky IV: Legume lectins and nodulation by Rhizobium. Trends 1997, 2:92-98.

48. Hirsch AM: Role of lectins (and rhizobial exopolysaccharides) in legume nodulation. Curr Opin Plant Biol 1999, 2:320-326.

49. Navarro-Gochicoa MT, Camut S, Timmers AC, Niebel A, Herve C, Boutet E, Bono JJ, Imberty A, Cullimore JV: Characterization of four lectin-like receptor kinases expressed in roots of Medicago truncatula. Structure, location, regulation of expression, and potential role in the symbiosis with Sinorhizobium eliloti. Plant Physiol 2003, 133:1893-1910.

50. Babosha AV: Inducible lectins and plant resistance to pPathogens and abiotic stress. Biochem (Moscow) 2008, 73:812-825. 
51. Spadoro-Tank PJoanne, Etzler EMarilynn: Heath shock enhances the synthesis of a lectin-related protein in Dolichos biflorus cell suspension cultures. Plant Physiol 1988, 88:1131-1135.

52. Cammue BP, Broekaert WF, Kellens JT, Raikhel NV, Peumans WJ: Stressinduced accumulation of wheat germ agglutinin and abscisic acid in roots of wheat seedlings. Plant Physiol 1989, 91:1432-1435.

53. Shakirova FM, Bezrukova MV, Shayakhmetov F: Effect of temperature shock on the dynamics of abscisic acid and wheat germ agglutinin accumulation in wheat cell culture. Plant Growth Regulation 1996, 19:85-87.

54. Hirano K, Teraoka T, Yamanaka H, Harashima A, Kunisaki A, Takahashi H, Hosokawa D: Novel mannose-binding rice lectin composed of some isolectins and its relation to a stress-inducible salT gene. Plant Cell Physiol 2000, 41:258-267.

55. Zhang W, Peumans WJ, Barre A, Astoul $C H$, Rovira $P$, Rougé $P$, Proost $P$, Truffa-Bachi $P$, Jalali AA, Van Damme EJ: Isolation and characterization of a jacalin-related mannose-binding lectin from salt-stressed rice (Oryza sativa) plants. Planta 2000, 210:970-978.

56. Abebe T, Skadsen RW, Kaeppler HF: A proximal upstream sequence controls tissue-specific expression of Lem2, a salicylate-inducible barley lectin-like gene. Planta 2005, 221:170-183.

57. Nobuta K, Venu RC, Lu C, Belo A, Vemaraju K, Kulkarni K, Wang W, Pillay M, Green PJ, Wang $G L$, et al: An expression atlas of rice mRNAs and small RNAs. Nat Biotechnol 2007, 25:473-477.

58. Finn RD, Mistry J, Schuster-Böckler B, Griffiths-Jones S, Hollich V, Lassmann T, Moxon S, Marshall M, Khanna A, Durbin R, et al: Pfam: clans, web tools and services. Nucleic Acids Res 2006, 34:D247-251.

59. Letunic I, Doerks T, Bork P: SMART 6: recent updates and new developments. Nucleic Acids Res 2009, 37 Database: D229-D232

60. Dinant S, Clark AM, Zhu Y, Vilaine F, Palauqui JC, Kusiak C, Thompson GA: Diversity of the superfamily of phloem lectins (phloem protein 2) in angiosperms. Plant Physiol 2003, 131:114-128.

61. Fouquaert E, Peumans WJ, Smith DF, Proost P, Savvides SN, Van Damme EJ: The "old" Euonymus europaeus agglutinin represents a novel family of ubiquitous plant proteins. Plant Physiol 2008, 147:1316-1324.

62. Pacak F, Kocourek J: Studies on phytohemagglutinins. XXV. Isolation and characterization of hemagglutinins of the spindle tree seeds (Evonymus europaea L.). Biochimica et Biophysica Acta 1975, 400:374-386.

63. Mulder N, Apweiler R: InterPro and InterProScan: tools for protein sequence classification and comparison. Methods Mol Biol 2007, 396:59-70.

64. Shridhar S, Chattopadhyay D, Yadav G: PLecDom: a program for identification and analysis of plant lectin domains. Nucleic Acids Res 2009, 37:W452-458.

65. Jia $X Y, H e L H$, Jing RL, Li RZ: Calreticulin: conserved protein and diverse functions in plants. Physiol Plant 2009, 136:127-138.

66. Dodd RB, Drickamer K: Lectin-like proteins in model organisms: implications for evolution of carbohydrate-binding activity. Glycobiology 2001, 11:71R-79R.

67. Xing $L$, Li J, Xu Y, Xu Z, Chong K: Phosphorylation modification of wheat lectin VER2 is associated with vernalization-induced O-GICNAc signaling and intracellular motility. PLOS One 2009, 4:e4854

68. Shiu SH, Karlowski WM, Pan R, Tzeng YH, Mayer KF, Li WH: Comparative analysis of the receptor-like kinase family in Arabidopsis and rice. Plant Cell 2004, 16:1220-1234.

69. Blanc G, Hokamp K, Wolfe KH: A recent polyploidy superimposed on older large-scale duplications in the Arabidopsis genome. Genome Res 2003, 13:137-144.

70. Vandepoele K, Simillion C, Peer Van de Y: Evidence that rice and other cereals are ancient aneuploids. Plant Cell 2003, 15:2192-2202.

71. Kong H, Landherr LL, Frohlich MW, Leebens-Mack J, Ma H, dePamphilis CW: Patterns of gene duplication in the plant SKP1 gene family in angiosperms: evidence for multiple mechanisms of rapid gene birth. Plant J 2007, 50:873-885.

72. Rizzon C, Ponger L, Gaut BS: Striking similarities in the genomic distribution of tandemly arrayed genes in Arabidopsis and rice. PLOS Comput Biol 2006, 2:e115.

73. Lin H, Zhu W, Silva JC, Gu X, Buell CR: Intron gain and loss in segmentally duplicated genes in rice. Genome Biol 2006, 7:R41.
74. Cannon SB, Mitra A, Baumgarten A, Young ND, May G: The roles of segmental and tandem gene duplication in the evolution of large gene families in Arabidopsis thaliana. BMC Plant Biol 2004, 4:10.

75. Chaw SM, Chang CC, Chen HL, Li WH: Dating the monocot-dicot divergence and the origin of core eudicots using whole chloroplast genomes. J Mol Evol 2004, 58:424-441.

76. Davies TJ, Barraclough TG, Chase MW, Soltis PS, Soltis DE, Savolainen V: Darwin's abominable mystery: insights from a supertree of the angiosperms. Proc Natl Acad Sci USA 2004, 101:1904-1909.

77. Anderson CL, Bremer K, Friis EM: Dating phylogenetically basal eudicots using rbcL sequences and multiple fossil reference points. Am J Bot 2005, 92:1737-1748.

78. Lynch $\mathrm{M}$, Conery JS: The evolutionary fate and consequences of duplicate genes. Science 2000, 290:1151-1155.

79. Jiang N, Bao Z, Zhang X, Eddy SR, Wessler SR: Pack-MULE transposable elements mediate gene evolution in plants. Nature 2004, 431:569-573.

80. Juretic N, Hoen DR, Huynh ML, Harrison PM, Bureau TE: The evolutionary fate of MULE-mediated duplications of host gene fragments in rice. Genome Res 2005, 15:1292-1297.

81. Zhang Y, Wu Y, Liu Y, Han B: Computational identification of 69 retroposons in Arabidopsis. Plant Physiol 2005, 138:935-948.

82. Wang W, Zheng H, Fan C, Li J, Shi J, Cai Z, Zhang G, Liu D, Zhang J, Vang $S$, et al: High rate of chimeric gene origination by retroposition in plant genomes. Plant Cell 2006, 18:1791-802.

83. Hanada K, Zou C, Lehti-Shiu MD, Shinozaki K, Shiu SH: Importance of lineage-specific expansion of plant tandem duplicates in the adaptive response to environmental stimuli. Plant Physiol 2008, 148:993-1003.

84. Betran E, Thornton K, Long M: Retroposed new genes out of the $X$ in Drosophila. Genome Res 2002, 12:1854-1859.

85. Wang Z, Gerstein M, Snyder M: RNA-Seq: a revolutionary tool for transcriptomics. Nat Rev Genet 2009, 10:57-63.

86. Barrett T, Troup DB, Wilhite SE, Ledoux P, Rudnev D, Evangelista C, Kim IF, Soboleva A, Tomashevsky M, Marshall KA, et al: NCBI GEO: archive for high-throughput functional genomic data. Nucleic Acids Res 2009, 37: D885-890.

87. Parkinson H, Kapushesky M, Kolesnikov N, Rustici G, Shojatalab M, Abeygunawardena N, Berube H, Dylag M, Emam I, Farne A, et al: ArrayExpress update-from an archive of functional genomics experiments to the atlas of gene expression. Nucleic Acids Res 2009, 37: D868-872.

88. Brechenmacher L, Kim MY, Benitez M, Li M, Joshi T, Calla B, Lee MP, Libault M, Vodkin LO, Xu D, Lee SH, Clough SJ, Stacey G: Transcription profiling of soybean nodulation by Bradyrhizobium japonicum. Mol Plant Microbe Interact 2008, 21:631-645.

89. Lannoo N, Peumans WJ, Van Damme EJ: Do F-box proteins with a Cterminal domain homologous with the tobacco lectin play a role in protein degradation in plants?. Biochem Soc Trans 2008, 36(Pt 5):843-847.

90. Apic G, Gough J, Teichmann SA: Domain combinations in archaeal, eubacterial and eukaryotic proteomes. J Mol Biol 2001, 310:311-325.

91. Chothia C, Gough J, Vogel C, Teichmann SA: Evolution of the protein repertoire. Science 2003, 300:1701-1703.

92. Lehti-Shiu MD, Zou C, Hanada K, Shiu SH: Evolutionary history and stress regulation of plant receptor-like kinase/pelle genes. Plant Physiol 2009, 150:12-26.

93. Thompson JD, Gibson TJ, Plewniak F, Jeanmougin F, Higgins DG: The ClustalX windows interface: flexible strategies for multiple sequence alignment aided by quality analysis tools. Nucleic Acids Res 1997, 25:4876-4882.

94. Huelsenbeck JP, Ronquist F: Bayesian inference of phylogenetic trees. Bioinformatics 2001, 17:754-755.

95. Jiang SY, Ramachandran S: Comparative and evolutionary analysis of genes encoding small GTPases and their activating proteins in eukaryotic genomes. Physiol Genomics 2006, 24:235-251.

96. Simillion C, Vandepoele K, Van Montagu MC, Zabeau M, Peer van de Y: The hidden duplication past of Arabidopsis thaliana. Proc Natl Acad Sci USA 2002, 99:13627-13632.

97. Jiang SY, Christoffels A, Ramamoorthy M, Ramachandran S: Expansion mechanisms and functional annotations of hypothetical genes in rice genome. Plant 2009, 150:1997-2008. 
98. Ithal N, Recknor J, Nettleton D, Hearne L, Maier T, Baum TJ, Mitchum MG: Parallel genome-wide expression profiling of host and pathogen during soybean cyst nematode infection of soybean. Mol Plant Microbe Interact 2007, 20:293-305.

99. Matsui A, Ishida J, Morosawa T, Mochizuki Y, Kaminuma E, Endo TA, Okamoto M, Nambara E, Nakajima M, Kawashima M, et al: Arabidopsis transcriptome analysis under drought, cold, high-salinity and ABA treatment conditions using a tiling array. Plant Cell Physiol 2008, 49:1135-1149.

100. Meyers BC, Tej SS, Vu TH, Haudenschild CD, Agrawal V, Edberg SB, Ghazal H, Decola S: The use of MPSS for whole- genome transcriptional analysis in Arabidopsis. Genome Res 2004, 14:1641-1653.

doi:10.1186/1471-2148-10-79

Cite this article as: Jiang et al:: Evolutionary history and stress regulation of the lectin superfamily in higher plants. BMC Evolutionary Biology 2010 10:79.

Submit your next manuscript to BioMed Central and take full advantage of:

- Convenient online submission

- Thorough peer review

- No space constraints or color figure charges

- Immediate publication on acceptance

- Inclusion in PubMed, CAS, Scopus and Google Scholar

- Research which is freely available for redistribution

Submit your manuscript at www.biomedcentral.com/submit 